NASA/TM—2007-214989

\title{
Development of Probabilistic Structural Analysis Integrated With Manufacturing Processes
}

Shantaram S. Pai

Glenn Research Center, Cleveland, Ohio

Vinod K. Nagpal

N\&R Engineering and Management Services Inc., Parma Heights, Ohio 


\section{NASA STI Program . . . in Profile}

Since its founding, NASA has been dedicated to the advancement of aeronautics and space science. The NASA Scientific and Technical Information (STI) program plays a key part in helping NASA maintain this important role.

The NASA STI Program operates under the auspices of the Agency Chief Information Officer. It collects, organizes, provides for archiving, and disseminates NASA's STI. The NASA STI program provides access to the NASA Aeronautics and Space Database and its public interface, the NASA Technical Reports Server, thus providing one of the largest collections of aeronautical and space science STI in the world. Results are published in both non-NASA channels and by NASA in the NASA STI Report Series, which includes the following report types:

- TECHNICAL PUBLICATION. Reports of completed research or a major significant phase of research that present the results of NASA programs and include extensive data or theoretical analysis. Includes compilations of significant scientific and technical data and information deemed to be of continuing reference value. NASA counterpart of peer-reviewed formal professional papers but has less stringent limitations on manuscript length and extent of graphic presentations.

- TECHNICAL MEMORANDUM. Scientific and technical findings that are preliminary or of specialized interest, e.g., quick release reports, working papers, and bibliographies that contain minimal annotation. Does not contain extensive analysis.

- CONTRACTOR REPORT. Scientific and technical findings by NASA-sponsored contractors and grantees.
- CONFERENCE PUBLICATION. Collected papers from scientific and technical conferences, symposia, seminars, or other meetings sponsored or cosponsored by NASA.

- SPECIAL PUBLICATION. Scientific, technical, or historical information from NASA programs, projects, and missions, often concerned with subjects having substantial public interest.

- TECHNICAL TRANSLATION. Englishlanguage translations of foreign scientific and technical material pertinent to NASA's mission.

Specialized services also include creating custom thesauri, building customized databases, organizing and publishing research results.

For more information about the NASA STI program, see the following:

- Access the NASA STI program home page at http://www.sti.nasa.gov

- E-mail your question via the Internet to help@sti.nasa.gov

- Fax your question to the NASA STI Help Desk at 301-621-0134

- Telephone the NASA STI Help Desk at 301-621-0390

- Write to: NASA Center for AeroSpace Information (CASI) 7115 Standard Drive Hanover, MD 21076-1320 


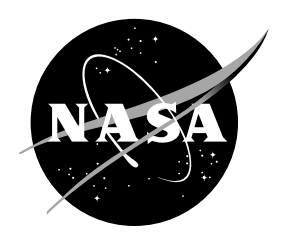

\section{Development of Probabilistic Structural Analysis Integrated With Manufacturing Processes}

Shantaram S. Pai

Glenn Research Center, Cleveland, Ohio

Vinod K. Nagpal

N\&R Engineering and Management Services Inc., Parma Heights, Ohio

Prepared for

Turbo Expo 2007

sponsored by the American Society of Mechanical Engineers

Montreal, Canada, May 14-17, 2007

National Aeronautics and

Space Administration

Glenn Research Center

Cleveland, Ohio 44135 


\section{Acknowledgments}

The work described in this paper was conducted under contracts from the National Aeronautics and Space Administration and Michigan Research Institute.

Level of Review: This material has been technically reviewed by technical management.

Available from

NASA Center for Aerospace Information 7115 Standard Drive

Hanover, MD 21076-1320
National Technical Information Service 5285 Port Royal Road Springfield, VA 22161

Available electronically at http://gltrs.grc.nasa.gov 


\title{
Development of Probabilistic Structural Analysis Integrated With Manufacturing Processes
}

\author{
Shantaram S. Pai \\ National Aeronautics and Space Administration \\ Glenn Research Center \\ Cleveland, Ohio 44135 \\ Vinod K. Nagpal \\ N\&R Engineering and Management Services, Inc. \\ Parma Heights, Ohio 44130
}

\begin{abstract}
An effort has been initiated to integrate manufacturing process simulations with probabilistic structural analyses in order to capture the important impacts of manufacturing uncertainties on component stress levels and life. Two physics-based manufacturing process models (one for powdered metal forging and the other for annular deformation resistance welding) have been linked to the NESSUS structural analysis code. This paper describes the methodology developed to perform this integration including several examples. Although this effort is still underway, particularly for full integration of a probabilistic analysis, the progress to date has been encouraging and a software interface that implements the methodology has been developed. The purpose of this paper is to report this preliminary development.
\end{abstract}

\section{Introduction}

Present day structural analysis performs either a deterministic or probabilistic calculation based on either a fixed set of mechanical properties and process parameters or the same properties and parameters with assumed distributions, respectively. The distribution characteristics of these variations are not necessarily reflective of the actual variation that may arise in practice. A preferred mode of using a set of probabilistic distributions is to collect this information from the actual manufacturing practices, say from the shop floor. Probably the single most important factor influencing these variations comes from the manufacturing processes. For example, processes such as welding, casting, forging etc. can cause large variations in the resulting mechanical properties due to operational variations in these processes, as well as the resulting variations in the state of the materials themselves. Therefore, having a quantitative understanding of these processes and integrating this information into a probabilistic calculation environment could lead to a much more realistic prediction of the structural response of a mechanical component in service. Specifically, it may lead to a more realistic assessment of the sensitivities of the mechanical properties and structural response, and how it is affected by variations in the manufacturing process.
During the last decade, NASA sponsored development of a general-purpose probabilistic finite element code entitled NESTEM that extends the basic capabilities of the NESSUS code to include heat transfer effects and composite material modeling. This code utilizes a number of approximate probabilistic methods based on the most probable point (MPP) approach, and can simulate uncertainties in the loading, geometry, material behavior, temperature and other userdefined uncertainties. These computationally efficient reliability methods in NESTEM provide a complete CDF solution with a minimum number of input perturbations. Therefore, performing a probabilistic analysis using NESTEM coupled to a general purpose manufacturing process modeling code, would provide a very efficient means of determining the reliability of a component that accounts for uncertainties in the manufacturing process.

Over the last couple of years, NASA initiated the development of applications of this probabilistic methodology to some of the important manufacturing processes (refs. 1 and 2). The tasks of this initiative were to, select a few manufacturing processes based on their importance to the industry, explore the operational parameters that control these processes, develop corresponding computer interfaces which would allow a user to set up a suitable environment to simulate such a process using a commercially available code named, DEFORM and, finally, to integrate this interface environment into NASA's probabilistic code, NESTEM, so that the user could use the tool to seamlessly simulate the manufacturing process and determine the importance of the controlling parameters in a probabilistic sense.

\section{Manufacturing Processes}

Two important manufacturing processes have been considered during the course of this work; namely, (a) a forging process and (b) the ADRW resistance welding process

\section{Forging Process}

Typically, based on the results of stress and strain, a probabilistic study of a forged powder metallurgy component, such as a rotating turbine disk, seeks to minimize stress, maximize 
fatigue life and minimize weight. The process of optimization could include an objective function to be minimized or maximized, which for the case of a forged disk would typically be stress in a particular region of the component and fatigue life of the component. Another consideration could be a set of design variables, such as the variables defining the geometry and material of the component that affect the objective function. Alternatively, it is possible to do an optimization analysis whereby a set of constraint conditions could be specified that allows the design variables to have some specific values. Such types of probabilistic analysis followed up by validation testing enables the development of a lighter forged powder disk, resulting in more efficient engines with higher reliability.

\section{ADRW Process}

Resistance heating is used for many different types of manufacturing processes, and welding of two parts has been one of them. However, joining of parts by this process has been primarily restricted to flat sheet type of components used in automotive and aerospace applications. When it comes to welding tubular products conventional welding processes may burn holes unless very precise control is in place. Also, round parts may need to be fixtured and/or turned during the joining process causing the cost and time to increase substantially. The Annular Deformation Resistance Welding (ADRW) process, sometimes known as simply the DRW process, was developed by taking advantage of the resistance heating process used in Resistance Spot Welding but it uses an annular electrode to handle tubular products (ref. 3). By using resistance heating, it raises the temperature of the joining surfaces locally to a high fraction of the homologous temperature. It also allows substantially high pressure to be applied at the joint so that the two joining surfaces can slide past each other causing a solid-state bond instead of the fusion nugget in Spot Welding, which involves melting and solidification. The quick heating takes the local joining surfaces to a plastic state and material from both work pieces mix. Thereby, a diffusion bond of fine grain forms. This is very important because the welding takes place in this case in a solid state and therefore, various combinations of dissimilar metals and alloys can be joined by this welding process. Even though this is a recently developed welding process, it has been successfully used to join tubes to solids, sheet metal and tubes of various sizes made of mild and stainless steel, as well as some nickel-based superalloys. The process has been shown to create leak-tight joints with superior strength in a much more rapid pace than conventional welding methods.

\section{Integration Methodology for a Manufac- turing Process}

Determining the combined effect of manufacturing process uncertainties and traditional structural uncertainties such as material properties and loading on structural integrity generally requires a computational framework that links the existing multiple simulation codes together. The "framework" in this case is a graphical user interface that enables users to specify input, invoke the codes in the proper sequence, and manage the information flow between them as described below (and depicted in fig. 1) so that a set of probabilistic responses can be evaluated for the manufacturing process:

Step 1: The first step is to select an appropriate finite element code, such as DEFORM, that will provide necessary results to simulate a manufacturing process of interest. Currently two specific choices of manufacturing processes have been considered, namely, powder forging and annular deformation resistance welding (ADRW).

Step 2: The next step is to generate a geometry model for the process using a general purpose CAD or finite element code such as ANSYS and then bring the model information seamlessly into the DEFORM environment. This is currently done with two graphical user interfaces (GUI), ForgProb and ProbDRAW, respectively for the powder forging and ADRW processes. Some of the operational parameters controlling the respective powder forging and ADRW process through which the probabilistic effects could be evaluated are discussed in detail in the appendix.

Step 3: This step requires the user to create a complete DEFORM model for the manufacturing process and execute it to perform a sequence of runs based on the variations of a set of input variables with probabilistic characteristics.

Step 4: The next step is to harvest the DEFORM manufacturing simulation output data to extract the response information required by NASA's probabilistic FPI code. FPI yields a probabilistic density function (PDF), a cumulative density function (CDF), and sensitivities to the design parameters and the operational parameters controlling the manufacturing process.

Step 5: Display the probabilistic output graphically as shown in figure 1 to enable designers to efficiently determine if a satisfactory design/manufacturing solution has been obtained. If constraint violations occurred or the design/ manufacturing solution is not adequately optimized, the designer may choose to make adjustments to either the design parameters or the manufacturing process parameters. In this case, steps $2-5$ are repeated iteratively until a satisfactory converged solution is obtained. The probabilistic sensitivity factors that are automatically calculated during this procedure help designers make appropriate design changes as well as help decision-makers allocate manufacturing resources wisely in situations requiring manufacturing modifications.

\section{Results}

In order to illustrate how this integrated probabilistic simulation procedure works, the results of two manufacturing process simulations are presented below. 


\section{ForgProb Simulation}

As a demonstration case we choose the plane strain model of an open block forging as shown in figures 2 and 3 . The forging work piece is considered to be a sintered porous IN718 superalloy, typically used for high temperature engine disk applications. Figure 4(a) and (b) shows non-dimensional flow stress variations of this material with temperature and strain at a low and high levels of strain rates. For this demonstration, we considered only a mechanical analysis at high temperature. Any accompanying heat transfer that would take place in a real environment has been ignored for simplicity. Both the top and bottom dies were considered to be rigid for the purpose of simulation. By invoking the "ForgProb" executable, we chose to work with ANSYS cdb models for the three objects in figure 3; namely, (a) Work piece as Object \#1, (b) Top die as Object \#2 and, (c) Bottom die as Object \#3. The material properties, required symmetry, inter-object conditions, simulation control, etc. are all input to complete the forging model at this stage. We consider that the top die moves 1 inch distance downward from its initial contact position with the work piece as shown. We also keep in mind that one needs to use all nominal conditions for the purpose of building this basic model of the forging process.

Figure 5(a) and (b) shows the initial and final shape of the porous perform after the top die is moved down by 1 in. Figure 6(a) to (c) shows the impact of variations of the initial density and the initial temperature of the forging piece. We consider that the density of the object will vary by 12.5 percent from its nominal value of 0.8 and that the temperature will vary by 2.85714 percent from its nominal value of $1750^{\circ} \mathrm{F}$. Preferably, the actual distributions for these control parameters need to be obtained from actual shop floor practices. However, as it has been done for the present case of demonstration, in the absence of available actual distributions, some sort of idealizations can produce meaningful results. As mentioned before, this model was for only non-thermal forging simulation and therefore, the HTC and the emissive parameters are ignored. The only effect of temperatures is reflected in deformation behavior of the work piece, as described in figure 5 .

After selecting a number of operational parameters and their variations (table 1), a series of DEFORM simulations starts automatically (one run after another for five times representing one nominal run and two for each variations in density (0.7 and 0.9) and in forging temperature (1700 and $\left.1800{ }^{\circ} \mathrm{F}\right)$. Figure 5(a) and (b) shows a snapshot of the undeformed and deformed meshes at the end of a run with initial relative density of 0.7 with a prescribed 1 inch top die movement. Figure 6 shows the density distribution in this block with starting relative density of $0.7,0.8$, and 0.9 , respectively with initial stock temperature set at its nominal value of 1750 ${ }^{\circ} \mathrm{F}$. The density varies from 0.74 to about 0.84 in the forging piece after $1 \mathrm{in}$. of compression in the case of starting density of 0.7. It is observed that the density at the end of forging with 0.8 and 0.9 starting density varies between 0.83 to 0.91 and
0.92 to 0.97 , respectively. A gradual intensification of density along classical slip bands is clearly observed. One observes that without including any heat transfer analysis for the forging setup, the effect of initial forging material temperature on density of compacted material is minimal.

Similarly, figure 7(a) to (d) shows strain rate distributions inside the work piece for an initial relative density of $0.7,0.8$, 0.9 and 1 (fully dense), respectively. The nominal work piece temperature was again $1750{ }^{\circ} \mathrm{F}$. For the case of 0.7 relative densities, the strain varies from 6.7 percent to 15.7 percent. This distribution varies from 7.7 percent to about 20 percent and from 8.5 percent to about 25.2 percent for starting density of 0.8 and 0.9 , respectively. This shows that a change in the initial stock density has significant effect on the strain distribution inside the material. It also shows that the initial material temperature has very little impact on the strain distribution inside the forged piece. To check the functioning of the simulation, we separately plotted the run simulation of the same model with an initial porosity of zero, i.e., fully dense and for fully plastic model. Figure 7(d) shows the strain distribution, which is in very close agreement with a separate simulation for porous work piece with relative density of 1 . Classical strain rate localization bands across the two diagonals are evident. All of these confirm the validity of the simulation runs through the ForgProb interface.

As shown in figure 8(a) to (d), the last set of results for this process represent the vertical loads on the top die for the various conditions. Figure 8 (a) to (c) shows the load versus top die movement for a starting material density of $0.7,0.8$, and 0.9 , respectively with a nominal material temperature of $1750{ }^{\circ} \mathrm{F}$. One observes a large increase in the load with increasing densities. But, in contrast with strain and strain rate distribution, this time there is a considerable effect of changing the initial work piece temperature. This again demonstrates the correct functioning of the DEFORM simulation remotely run through the ForgProb interface.

\section{ProbDRAW Simulation}

This section describes a real demonstration of how the "ProbDRAW" interface can be used to completely perform a series of DEFORM simulations starting with a set of IGES models representing various object geometries of a deformation resistance welding model.

In resistance heating, a controlled amount of electrical current or voltage is passed through two or more pieces of metal that have been pressed together, creating heat at the interface. The amount of heat generated is given by the fundamental electrical formula:

$$
\mathrm{Q}=\mathrm{I}^{2} \mathrm{Rt}
$$

Where, $\mathrm{Q}=$ heat generated in Joules, $\mathrm{I}=$ current in Amp, $\mathrm{R}=$ work piece electrical resistance in $\mathrm{Ohm}, \mathrm{t}=$ duration of current in seconds. 
Normally, the current and its duration are controlled by the resistance heating power supply. Also, the resistance of the interfaces and the bulk materials is a function of the force and the material. It is also true that a slight change in the level of current/voltage or time can greatly affect the heat generation, thereby affecting the temperature. For the purpose of this demonstration, we had the choice of current or voltage imposed boundary condition. Large electrode force and contact area result in low contact resistance. In contrast, low force and small contact area result in high contact resistance (ref. 4). If the contact resistance does not change much during the resistance heating related process, such as ADRW, using constant current control will result in predictable generation of heat. On the other hand, voltage control will be suitable for applications in which the parts being heated do not have flat surfaces and hence may start with less contact area in the beginning of deformation, which grows with deformation. This is expected to be the case for the ADRW process. In this situation, the contact resistance and hence the total resistance starts at high level so that heat generated starts out low because here,

$$
\mathrm{Q}=\left(\mathrm{V}^{2} / \mathrm{R}\right) \mathrm{t} \text {, where } \mathrm{V}=\text { voltage in Volts. }
$$

As the deformation increases contact area, the contact resistance decreases, thereby increasing heat generation. The end result in this scenario, therefore, is greater control over the amount of heat generated.

As a demonstration case we chose an axisymmetric model of a tube and plate-welding configuration as shown in figure 9(a). The tube is made of either IN625 superalloy or 316 Stainless Steel and is, 2 in. i.d. by 2.2 in. o.d. by 12 in. long. The annular plate is made of 316 Stainless steel, and is $2.25 \mathrm{in}$. i.d. by 6 in. o.d. by 0.1 in. thick. For the demonstration, we considered the ADRW process simulation in two steps; namely, (a) resistance heating, (b) applying pressure to the top electrode. Any accompanying heat transfer that takes place in a real environment has been considered in these analyses. Figure 9(b) and (c) shows two different perspectives of various objects that will make up a typical ADRW process to create the welded joint in figure 9(a). This figure represents the four objects; namely, the top and bottom annular electrodes, and the tube and annular thin plate. Both electrodes are made of $\mathrm{Cu}-1$ percent $\mathrm{Cr}$ alloy. The top electrode is 2.4 in. i.d. by 3 in. o.d. by 4.5 in. long annular tube. The bottom electrode is 2.3 in. i.d. by 2.9 in. o.d. by 1.5 in long annular tube. Figure 9(b) shows perspective views of the complete setup, as well as a magnified view of the cross-section (fig. 9(c)). Based on axisymmetric configuration of the four objects, respective igs and cdb files were created in ANSYS as geometry inputs.

By invoking the "ProbDRAW" module, we chose to import ANSYS IGES models and mesh models for the four objects described above in figure 9. Figure 10(a) shows how the whole model will look when all four objects are combined. Figure 10(b) shows the full DRW model after assembling the four objects meshes created in ANSYS.
After the geometric models are either imported or transformed into DEFORM compatible objects, the material properties, required symmetry, inter-object conditions, simulation control, et cetera are all input to complete the model at this stage. Figure 14(a) shows a local view of the mesh structure around the interfaces resulting from the fourbody contact. Figure 11(b) describes the time variation of the applied voltage and subsequent application of mechanical force as nominal input to the model. Figure 12(a) to (h) shows all the temperature dependent physical and mechanical properties used for the four objects. All of these data are simplified representations of the actual data. Therefore, these are approximate in nature and intended for demonstration calculations only. We consider that there is a voltage potential of $3 \mathrm{~V}$ applied between the top and bottom electrodes for the purpose of simulating the resistance heating in the setup. A typical example of how an ASCII file representing the variations of a number of operational parameters in an ADRW process will look like is shown in Table 2, where one-step variation on the nominal values of current flow time, applied voltage, mechanical force and interfacial resistivity are described. This has been included in the current interface with the notion that in possible future developments, one can make use of this text file to automatically conduct a series of simulation runs, the results of which will provide input to a probabilistic analysis.

For the purpose of this demonstration, however, we have performed simulations on an individual case basis in a serial fashion of resistance heating first (defined as Process 1), followed by the application of external pressure on the top electrode (defined as Process 2). Out of the seven parameters listed in the "Control Parameters" interface, we have varied four, namely current flow time, applied voltage, mechanical force, and interface resistivity by 10 percent from their respective nominal values of $2 \mathrm{sec}, 3 \mathrm{~V}, 28000 \mathrm{lb}$, and $0.01 \mathrm{ohm}-\mathrm{in}^{2}$. The nominal force has been calculated from an assumed pressure of $24 \mathrm{ksi}$ at the joining interface "AA" between the annular plate and the tube as shown in figure 11(a). As shown in figure 12(e), SS316 plate material becomes plastic beyond about $1000^{\circ} \mathrm{F}$. The assumed time profile of resistance heating for $2 \mathrm{sec}$, followed by the application of mechanical load on the top electrode for $10 \mathrm{sec}$ is shown in figure 11(b). We also took a look at the effect of welding between the plate and the tube with an assumption that both are made of SS316. It is also instructive to consider the effect of changing interfacial resistivity between the top electrode and the plate and/or the bottom electrode and the tube on the overall temperature distribution. The ASCII file corresponding to these four parameter variation in the control interface looks similar to table 2, where the description for the corresponding seven control parameters are shown in the left, followed by their respective values with the central value as the nominal.

We first present a detailed look at the simulation results for the case of welding a SS316 plate with IN625 tube with applied voltage of $3 \mathrm{~V}$ for $2 \mathrm{sec}$, followed by an applied load of $28000 \mathrm{lb}$ for $10 \mathrm{sec}$. The system is allowed to cool off at the 
end of heating period. We also applied a temperature boundary condition of $68^{\circ} \mathrm{F}$ at the top and bottom surface of the two electrodes since the DRW would utilize some sort of water cooling of the electrodes to keep its temperature controlled to a low level while heating. Some of these results are summarized in figure 13(a) to (d). These indicate that the maximum temperature reached by the interface under these operating conditions is $1310^{\circ} \mathrm{F}$, as shown in figure 13(a). Subsequent cooling off of the system, while the load has been applied by the heat generated, has been allowed to conduct through the various materials and convected to the surrounding. It shows that the system cools off to a temperature level of $365^{\circ} \mathrm{F}$ registered at some regions of the joining bodies.

Figure 13(b) is a snapshot of effective stress distribution inside the four objects at the end of $10 \mathrm{sec}$. cooling period, when the load is also simultaneously applied. It indicates that the joining surface region of the tube attains a stress level of $66.7 \mathrm{ksi}$. As the system then cools off while the load is in place, the material system sees a continued increase in stress level. These and other results show that at the tube interface the effective stress increases from $61.2 \mathrm{ksi}$ level at the end of heating to $66.7 \mathrm{ksi}$ level at the end of cooling. This phenomenon is due to residual stress buildup while cooling is taking place. Figure 13(c) shows the effective strain in the bodies at the end of load application and cooling. These plots clearly show that most of the straining is taking place in the SS316 plate because it is the softer of the two materials being joined. These results also indicate that the stress and strain get into the plastic state during and after DRW process. As reflected by the maximum principal stress plot in figure 13(d), the materials see both tensile as well as compressive stresses in the regions. A the end of any of these simulations, our interest is to understand the temperature, stress, and strain states around the interface between the plate and the tube (interface "AA" in fig. 11(a)) because these fundamental parameters along with time will determine the effectiveness of the welding process. Figure 14(a) to (c) is a snapshot of temperature, effective strain, and effective stress along this interface starting from inside. It shows that these values attain a much higher level at the inside than outside indicating the possibility of uneven joining. This also indicates the importance of proper design of the joints so that one can achieve a state of uniformity across the joining interface.

As an example of comparing these results at nominal voltage of 3, figure 15(a) to (d) shows the corresponding results of temperature, effective stress, and strain, principal stress at a 10 percent increased voltage level of 3.3 . In this case, as shown in figure 15(a), the maximum temperature at the interface reached a level of $1510^{\circ} \mathrm{F}$, which is $200^{\circ} \mathrm{F}$ hotter than the case of $\mathrm{V}=3$ (fig. 13(a)). This shows the high level of sensitivity of changing current/voltage through the system. Figure 15(b) to (d) shows the effective stress, effective strain, and maximum principal stress at the end of loading and cooling off. Interestingly, these results show that due to more heating in this case, the maximum strain increased from 0.9 to 1.1 percent at the interface, although the effective and maximum principal stress have both slightly decreased due to more softening of the materials. All of these results demonstrate the validity of ADRW process simulation runs through the ProbDRAW interface.

\section{Conclusion}

Representative axisymmetric and plane strain powder forgings and ADRW processes were analyzed using NESTEM compatible ANSYS $\mathrm{cdb}$ and igs files. The general-purpose deformation analysis program DEFORM was integrated with NESTEM to enable it to read these geometry files into its own environment with exact one-to-one correspondence. To facilitate this integration, two Windows-based graphical user interfaces (ProbDRAW and ForgProb) were developed to seamlessly simulate two manufacturing processes; namely, Deformation Resistance Welding and Powder Forging, respectively. The workability and accuracy of these interfaces were demonstrated through examples using realistic 2D axisymmetric and plane strain geometry models for these two processes. The development work up to this point has demonstrated that it will be possible to develop a robust integration between the NESTEM environment and a finite element based deformation simulation code, DEFORM, to perform probabilistic analysis of a porous forging, as well as deformation resistance welding processes. To move forward with this development, it is necessary to develop an understanding of the actual forging and solid state welding processes based on fundamental information obtained from these simulations, such as distribution of temperature and stresses, time, and faying surface features. Work along this line is currently in progress. 



\section{Appendix}

\section{$\underline{\text { Probabilistic Forging Simulation Interface }}$ (ForgProb)}

The objective of this interface is to integrate the NESTEM probabilistic code with a commercial general-purpose deformation analysis code, DEFORM ${ }^{\mathrm{TM}}$. A keyword file provides the baseline problem setup and a corresponding text file specifies different variations from the baseline. This ASCII file is created from the "Control Parameters" form displayed (fig. 16) through the main "ForgProb" interface. There are currently seven process variables and boundary conditions that can be varied. These are:

(a) Initial density of the forging work piece as governed by its initial porosity level. This is actually the relative density defined as the density of the porous work piece divided by the fully dense material density. Thus, the maximum value of this parameter is 1 when the work piece is fully dense. The current formulation of DEFORM, however, allows this variable to have values from 0.7 to 1 , indicating that processes such as green body compaction cannot be considered under this framework. The powder forging process involved with porous sintered compaction is fully adaptable in this framework and is the main process of interest in the current work.

(b) Initial stock temperature, which indicates the forging piece temperature at the beginning of forging process.

(c) Interface heat transfer coefficient between the work piece and the dies. This value can be prescribed in a variety of ways reflecting actual forging process techniques and shop conditions.

(d) Surface emissivity - depending on the surface conditions of the various components, the heat transfer characteristics of the process can be significantly controlled and therefore this variable can also have a large impact of the process variability.

(e) Initial die temperature-like the stock temperature, this variable can be varied and its effect determined.

(f) Friction coefficient between work piece and die - the friction coefficient may be prescribed in a number of ways and represents the contact conditions between the work piece and the dies. It can have a significant impact on the quality and forge ability.

(g) Top die speed - typically the velocity of the top die controls the forging process and the effect of its variation can be evaluated.

The user can select any combination of these variables as determined by the relevance of the powder forging process and other factors unique to the functional requirements of the forged component. The first column of cells is for the nominal value of the corresponding variables. The second and third columns are for the desired \pm percent change in the respective parameters and the corresponding number of steps to create these changes from the nominal value. For example, Table 1 was created with only two parameters for which the effect of variations are calculated and reported here. The set of analysis results shown in the results section were only for variations of initial stock density and initial stock temperature. The other five variables did not have any variation and therefore had only nominal values prescribed through the respective dialog boxes.

\section{Probabilistic Deformation Resistance $\underline{\text { Annular Welding }}$ (ProbDRAW)}

Utilizing the same architecture of the "ForgProb" interface, the objective of this interface is to ultimately integrate the NESTEM code with the commercial code DEFORM to perform probabilistic analyses of Deformation Resistance Welding processes.

By selecting the "Control Parameters" submenu item, a new window entitled "Control Parameters" is displayed (fig. 17), that allows specification of a set of desired process parameters that can be utilized to run a series of DEFORM simulations for the ADRW process. That is, this window provides the opportunity to prescribe the definitions of a series of process parameters on which the probabilistic sensitivity study will subsequently be made. The parameters in this interface are representative of a whole set that can be defined in a text file and analyzed based on topics of interest to the user. There are currently seven process variables and boundary conditions that may be varied. These are:

(a) Current flow time, which provides input for the desired resistance heating time in seconds.

(b) Applied voltage, which specifies the voltage level used during the welding process.

(c) Time of hold force, which specifies how long the external force/pressure is intended to be applied on the electrode.

(d) Mechanical force, which provides the level of force in $\mathrm{Klb}$ applied on the top of the top electrode for creating a large pressure on the joining interface.

(e) and (f) Electrical resistivity for the two work pieces.

(g) Interfacial electrical resistivity between the two work pieces. This value can be prescribed in a variety of ways, reflecting the actual surface condition of the two faying surfaces.

The user can select any combination of these variables as determined by the relevance of the deformation resistance welding process and other factors unique to the functional requirements of the welded component. The first column of cells is for the nominal value of the corresponding variables. The second and third columns are for the desired \pm percent change in the respective parameters and the corresponding number of steps to create these changes from the nominal value. For example, Table 2 was created with only four parameters for which the effect of variations are calculated and reported here. The actual text file created will have the names of the parameters shown as their respective DEFORM keywords. The set of analysis results shown in the results section are only for variations of time for current flow, applied pressure, applied voltage, and interface resistivity. The other three variables (pressure hold time, the two work piece bulk resistivities) did not have any variation and therefore only have nominal values. 


\section{References}

1. Development of Probabilistic Structural Analysis Integrated with Deformation Resistance Annular Welding Simulation (ProbDRAW), Phase I N\&R Engineering Report to NASA GRC Contract NAS3-01168.

2. Development of Probabilistic Structural Analysis Integrated with Deformation Resistance Annular Welding Simulation (ProbDRAW), Phase II N\&R Engineering Report to Michigan Research Institute Contract.

3. A. Ananthanarayanan, "Resistance welding tackles tubes," Machine Design, Oct. 2003.

4. R. Holm, "Electric Contacts: Theory and Application," 1967, Springer-Verlag, NY.

\section{TABLE 1.-INPUT CREATED FROM "FORGPROB"} CONTROL PARAMETER INTERFACE

Initial Stock Density, relative.

0.70 .80 .9

Work Piece Temperature, ${ }^{\circ} \mathrm{F}$ 170017501800

Die \& Work Piece HTC

Surface Emissivity....

,

Initial Die Temperature, ${ }^{\circ} \mathrm{F}$..

. .68

Die and Work Piece Friction Coefficient 0.08

Top Die Speed
TABLE 2.-INPUT CREATED FROM "PROBDRAW" CONTROL PARAMETER INTERFACE

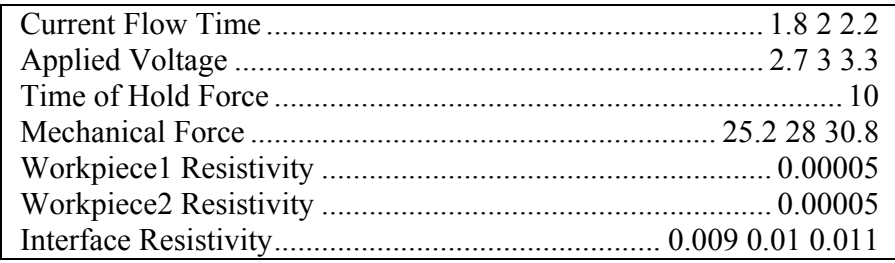

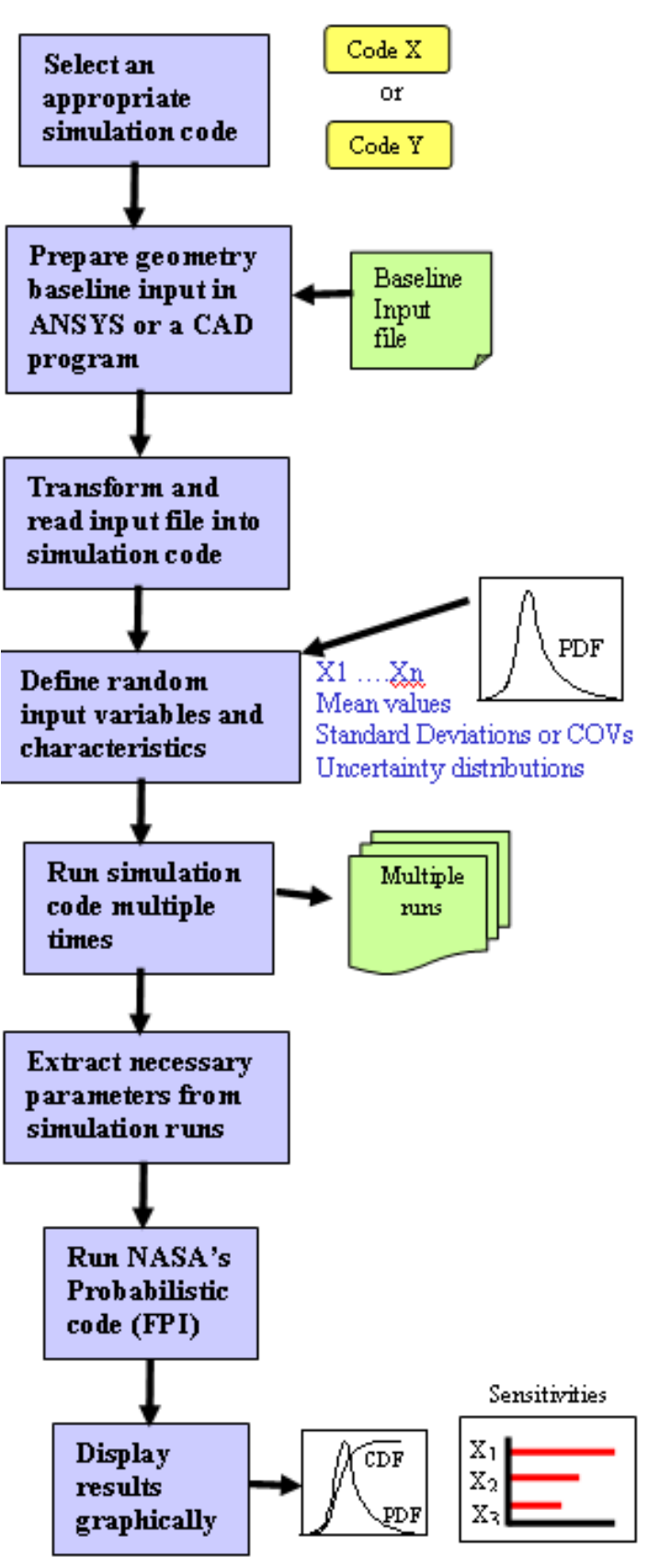

Figure 1.-A schematic representation of the software integration methodology adopted in this development work. 


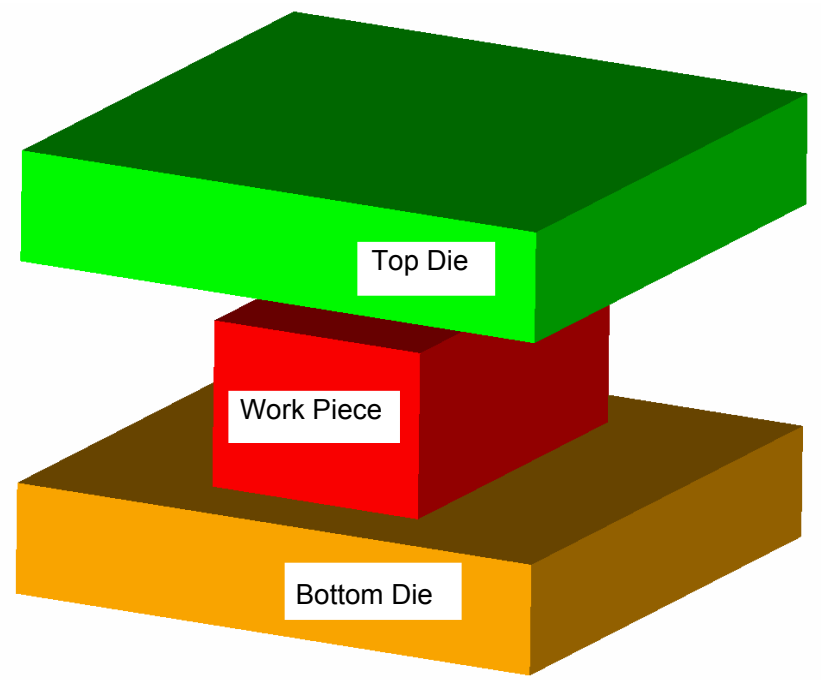

Figure 2.-Schematic 3-D perspective of a simple blockshaped forging work piece configuration.

Top Die

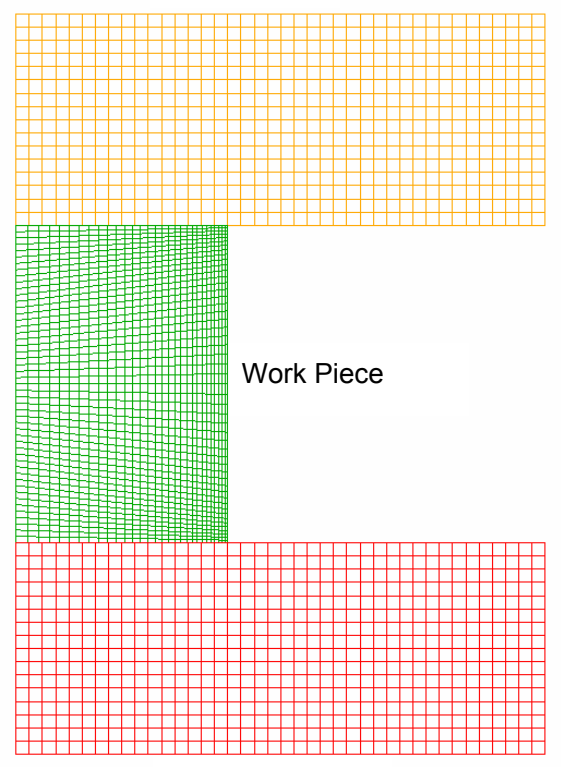

Bottom Die

Figure 3.-Meshed configuration of the plane-strain model using 4-noded quad elements.
Flow stress $=\mathrm{f}$ (strain, temperature)

@ lower strain rate

(a)

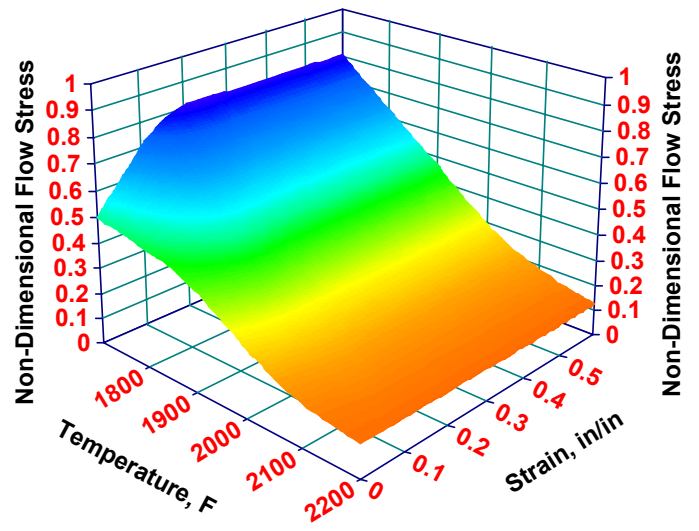

Flow stress = $\mathrm{f}$ (strain, temperature) @ higher strain rate

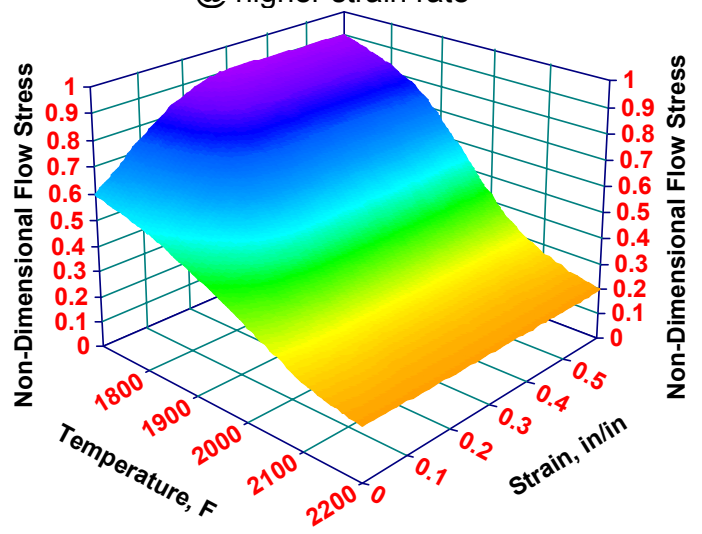

(b)

Figure 4.-Typical levels of non-dimensional flow stress of IN-718 superalloy at low and high strain rates.

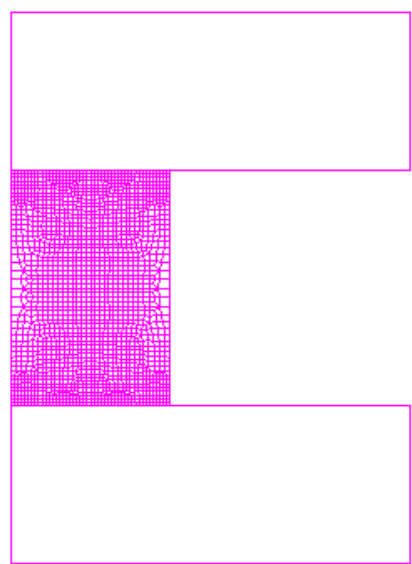

(a)

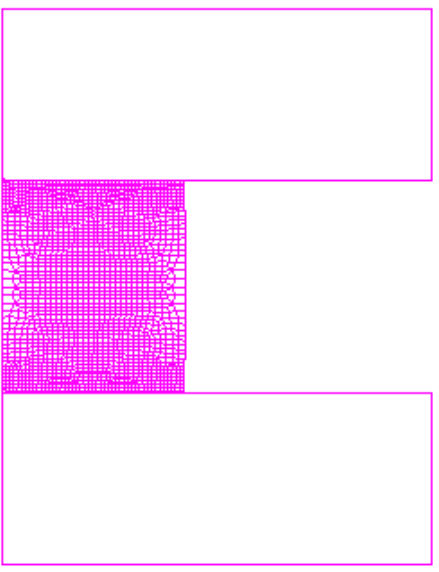

(b)
Figure 5.-(a) Initial mesh of the work piece with rigid dies, (b) Deformed mesh after the top die has moved down by 1 in. 


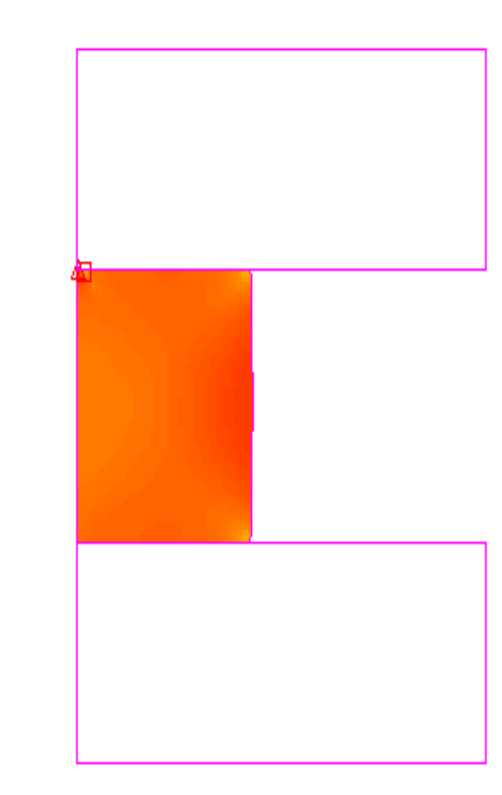

(a)

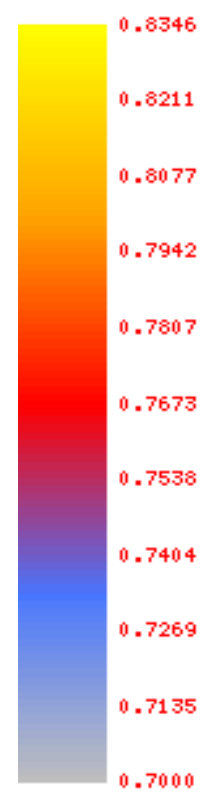

0.7000

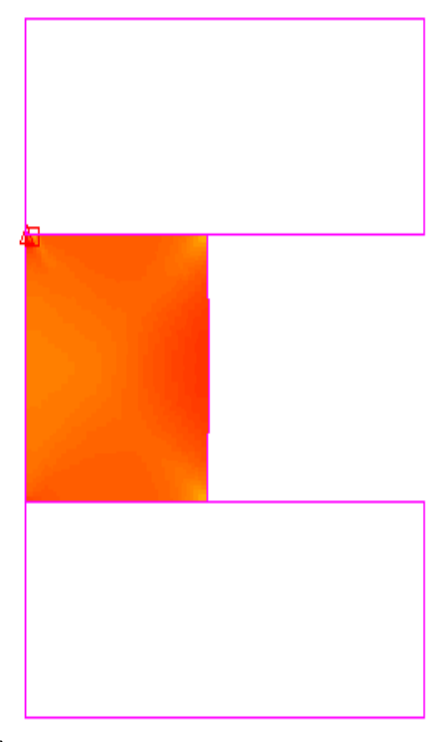

(c)

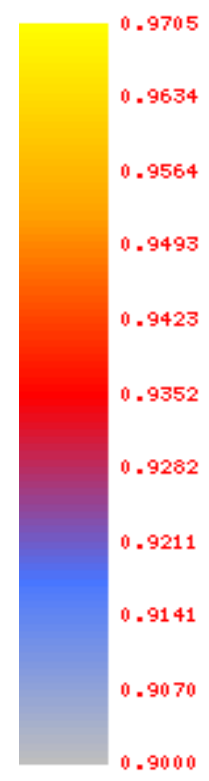

Figure 6.-(a) Initial relative density of 0.7 . The density varies from 0.74 to about 0.84 in the forging piece after 1 in. of compression, (b) Initial relative density of 0.8 . The density of the stock after 1 in. of die compression varies from 0.83 to about 0.91 , (c) Initial relative density of 0.9 . The density of the stock after 1 in. of die compression varies from 0.92 to about 0.97 . Initial stock temperature is $1750{ }^{\circ} \mathrm{F}$. 


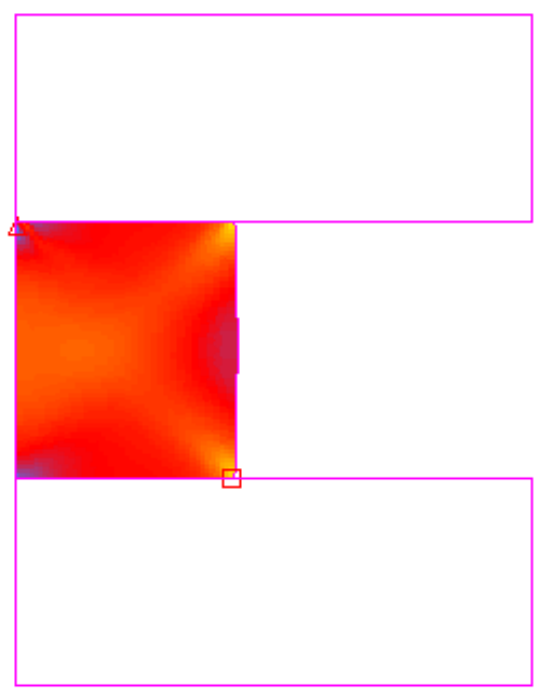

(a)

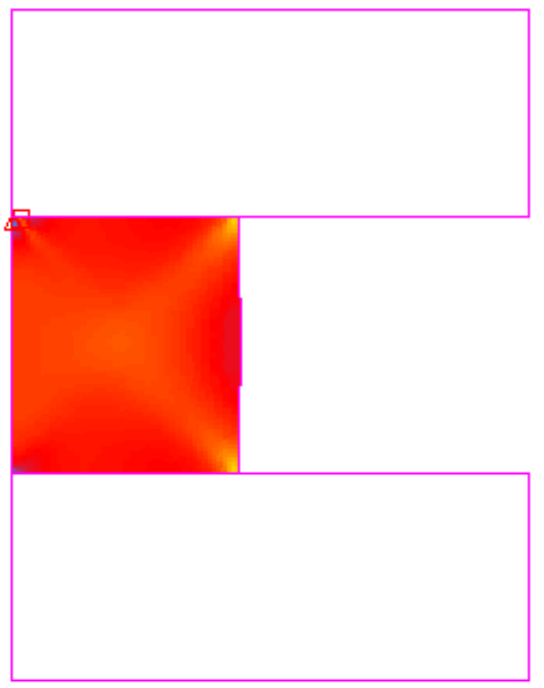

(b)
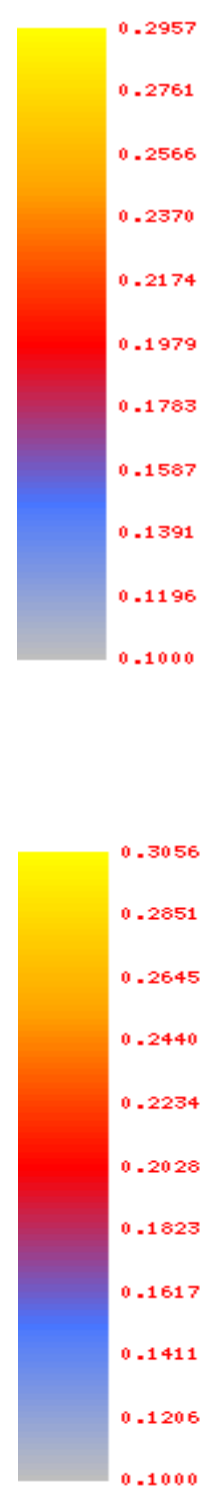
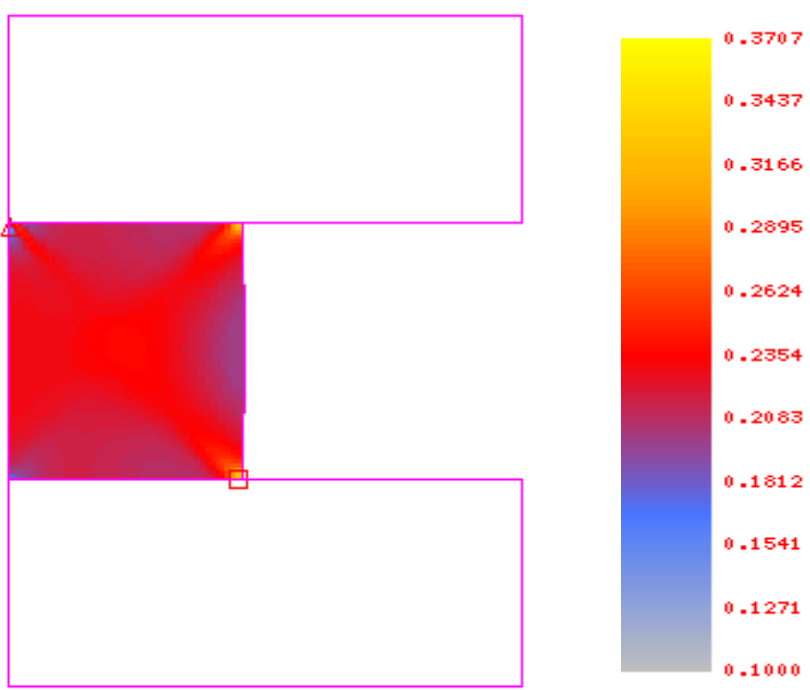

(c)
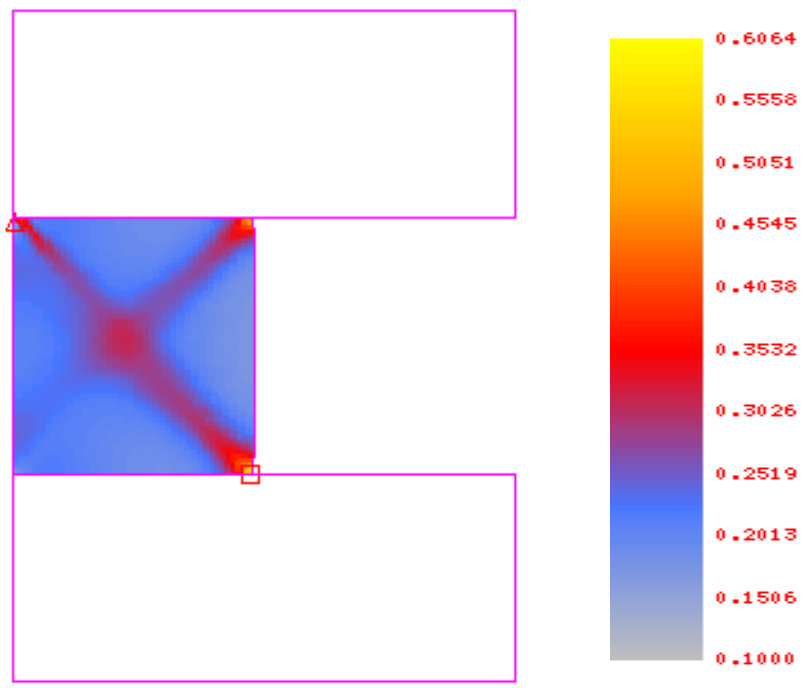

(d)

Figure 7.-(a) Relative density of 0.7 . The strain rate distribution in the stock after 1 in. of die compression varies from 12 to about 30 , (b) Relative density of 0.8 . The strain rate distribution in the stock after $1 \mathrm{in}$. of die compression varies from 11 to about 30 ,

(c) Relative density of 0.9 . The strain rate distribution in the stock after 1 in. of die compression varies from 10 to about 37 ,

(d) With no porosity, i.e., fully dense. The strain rate distribution in the stock after 1 in. of die compression varies from 10.5 to about 60.6. Initial stock temperature is $1750^{\circ} \mathrm{F}$ for all cases. All rates are in percent/sec. 
(a)
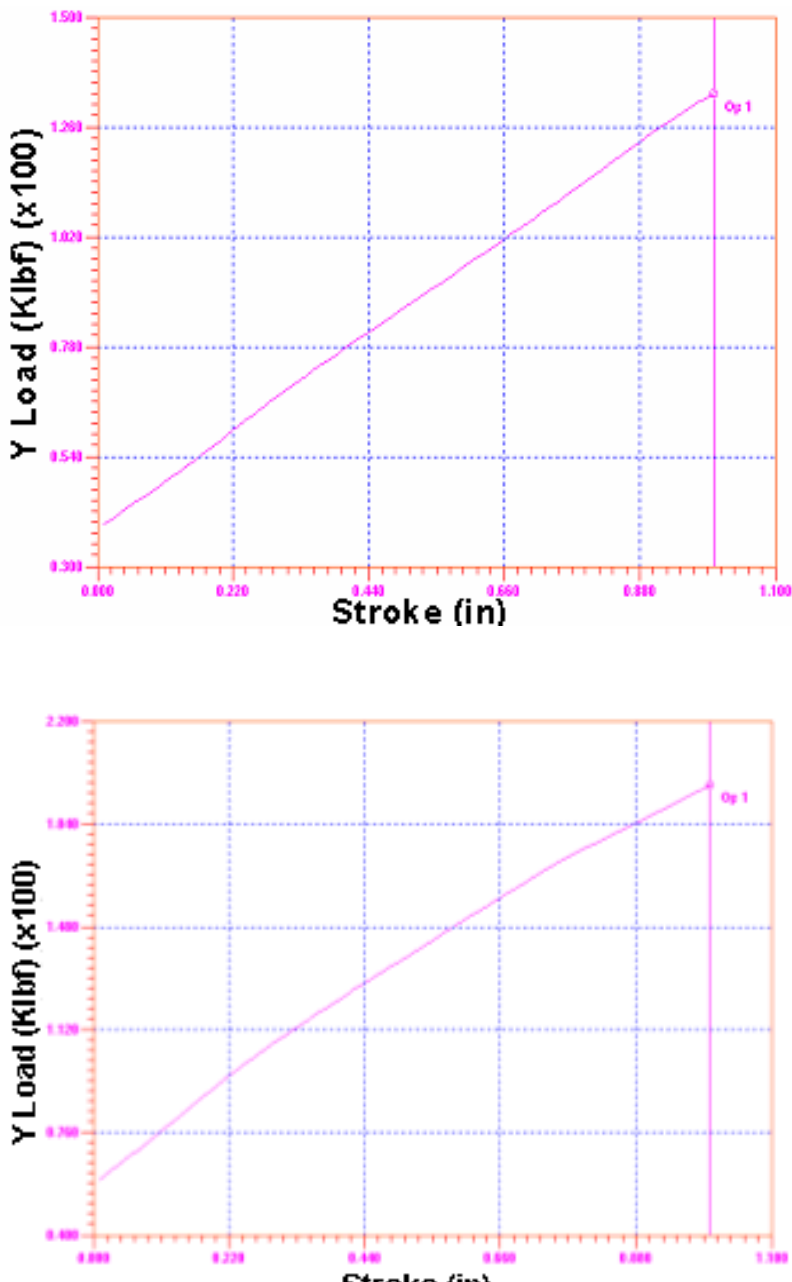

(b)

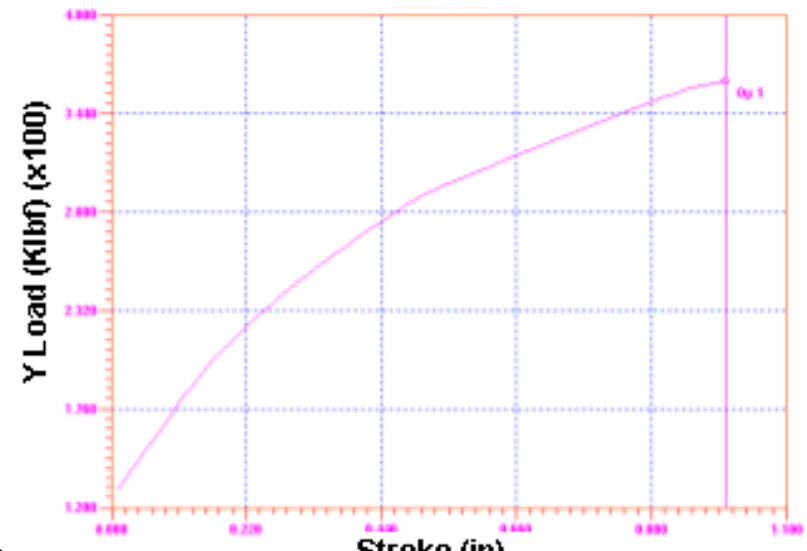

(c)

(d)

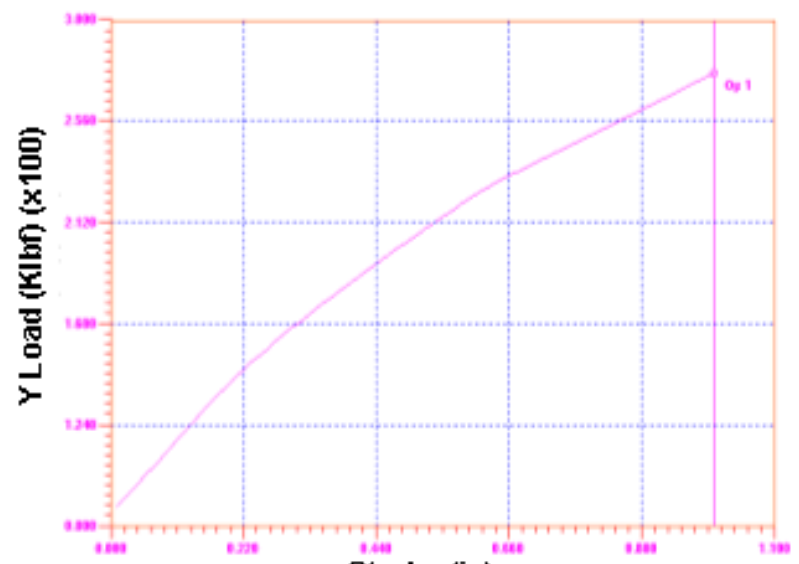

Stroke (in)

Figure 8.-(a) Vertical load versus die movement plot for material with initial relative density of 0.7 . After 1 in. of die movement, the load is about $135 \mathrm{klb}$., (b) Initial relative density of 0.8 . After 1 in. of die movement, the load goes up to about $200 \mathrm{klb}$, (c) Initial relative density of 0.9 . After 1 in. of die movement, the load goes up to about $280 \mathrm{klb}$, (d) With no initial porosity, i.e., fully dense. After 1 in. of die movement, the load goes up to about $365 \mathrm{klb}$. Initial stock temperature of $1750{ }^{\circ} \mathrm{F}$. 


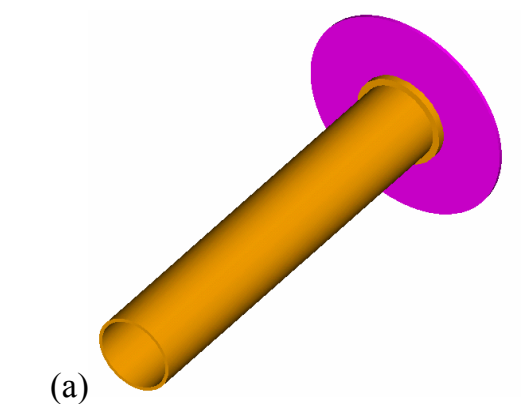

(a)

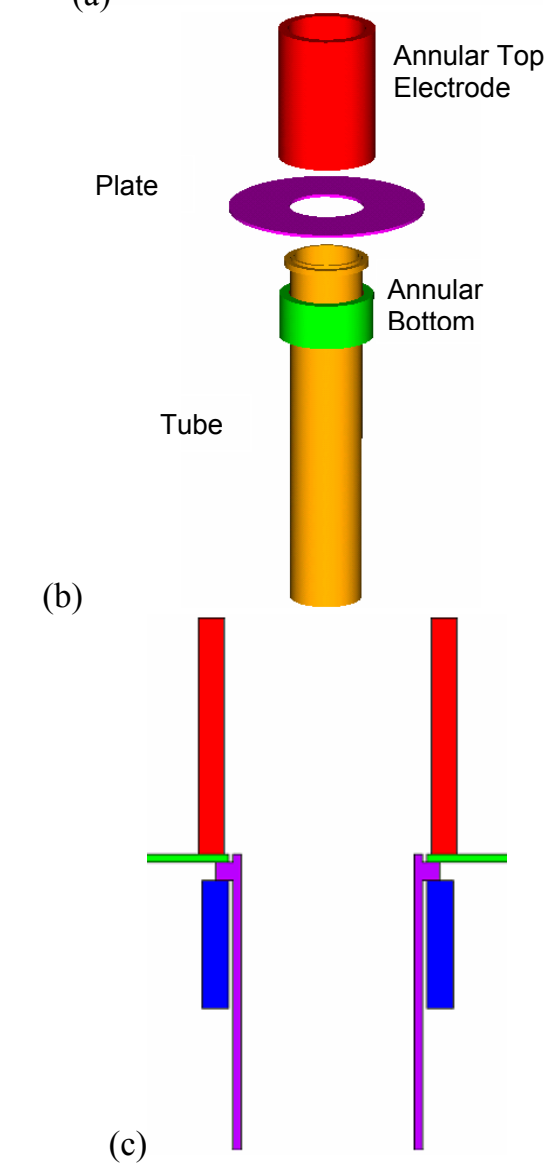

Figure 9.-(a) Schematic 3D perspective of a simple welded tube on an annular plate, (b) an axisymmetric model of the setup, along with top and bottom electrode, and (c) crosssectional view showing relative positioning of the tube, plate and the two electrodes

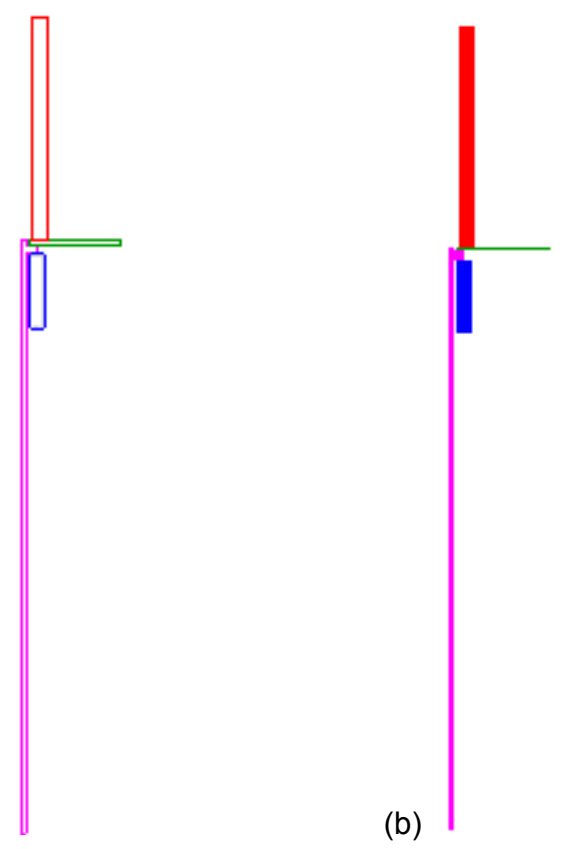

Figure 10.-(a) Snapshot of DEFORM preprocessor display interface after all the IGES files of the four axisymmetric objects are imported into DEFORM code, (b) Snapshot of all four meshed models that were converted from the respective .cdb models and brought into the DEFORM environment

(a)

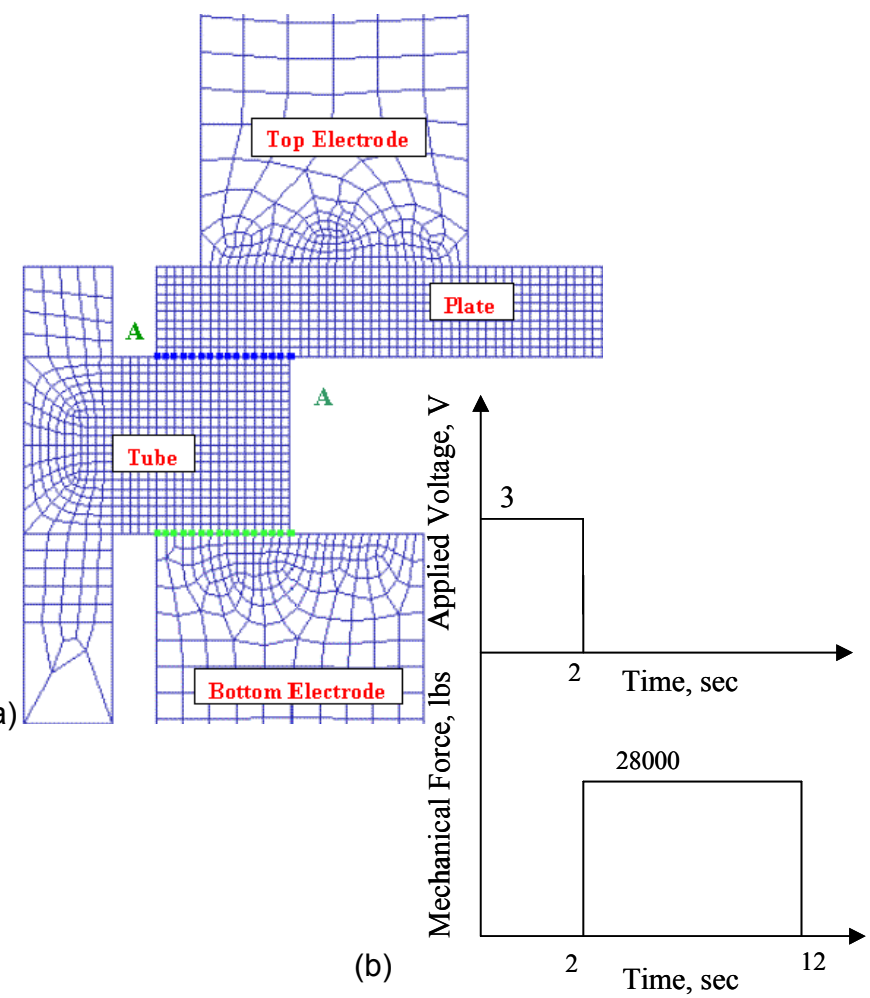

Figure 11.-(a) Detailed look at the interfaces of the various objects of the model, particularly the interface between the plate and the tube, (b) applied voltage and mechanical pressure load versus time 

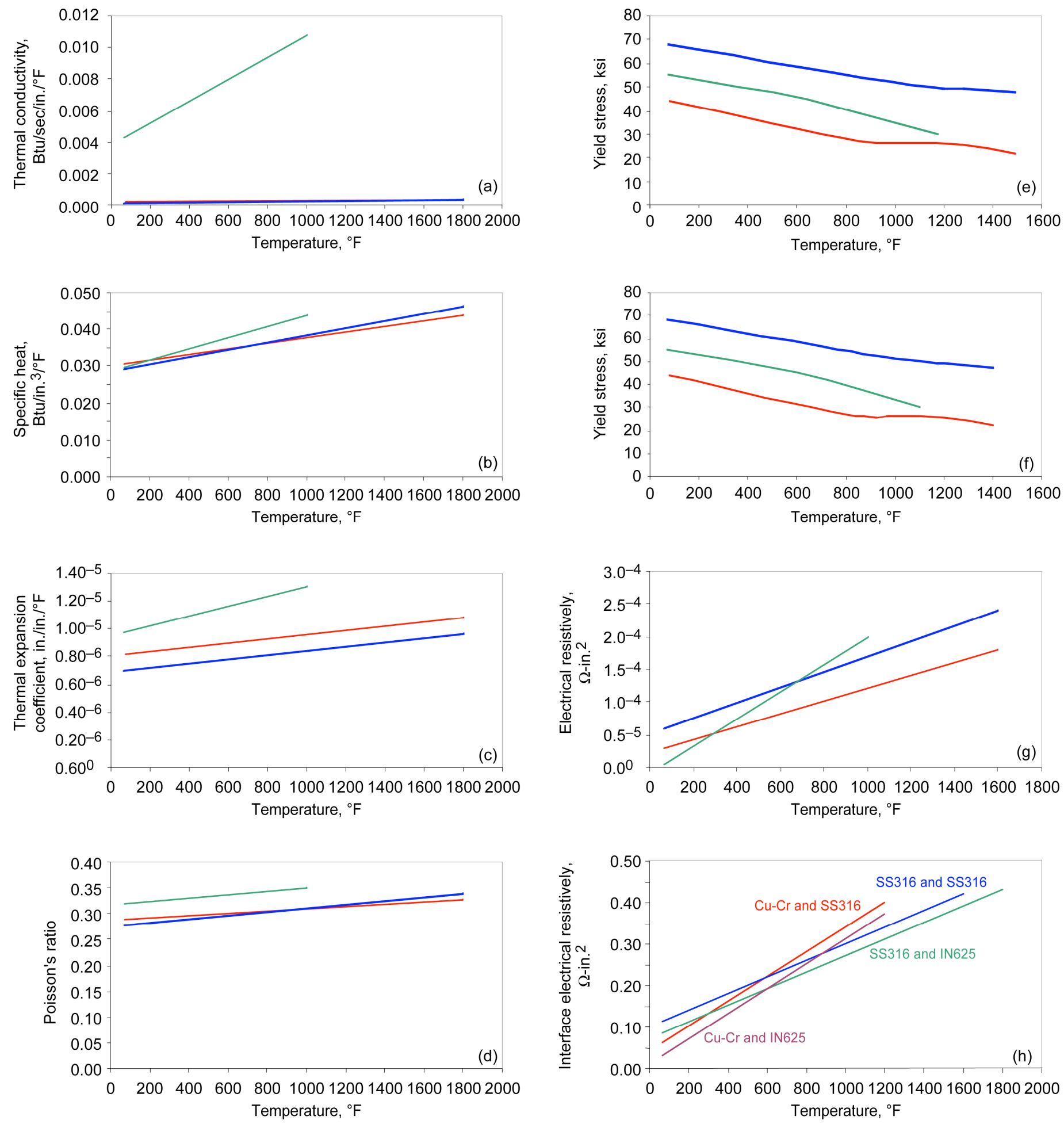

Figure 12.-Approximate temperature dependence of various properties of the electrode, plate and tube materials needed for deformation resistance simulation, (a) thermal conductivity, (b) specific heat, (c) thermal expansion coefficient, (d) Poisson's ratio, (e) yield stress, (f) Young's modulus, (g) bulk electrical resistively and, (h) interface electrical resistively. Color codes in (a) - (g): Red-SS 316, Blue-IN 625 and Green-Cu+Cr 


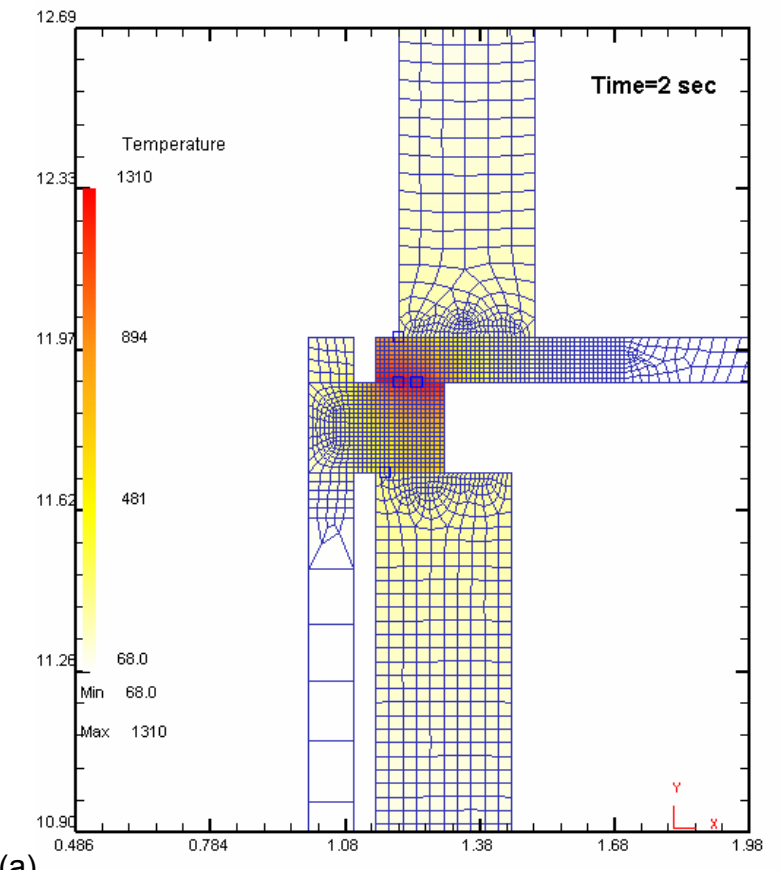

(a)

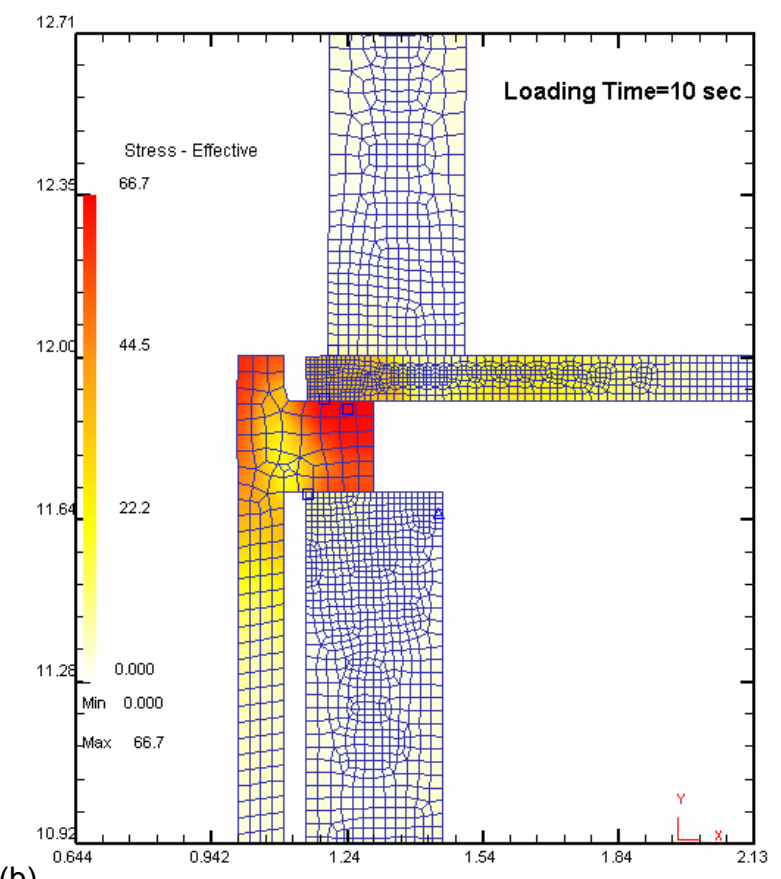

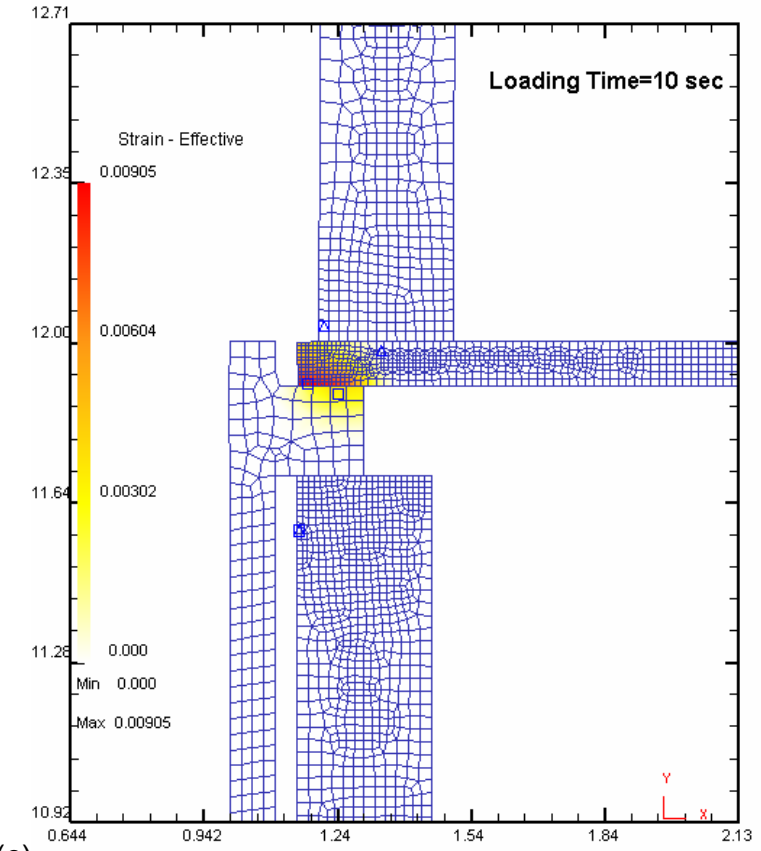

(c)

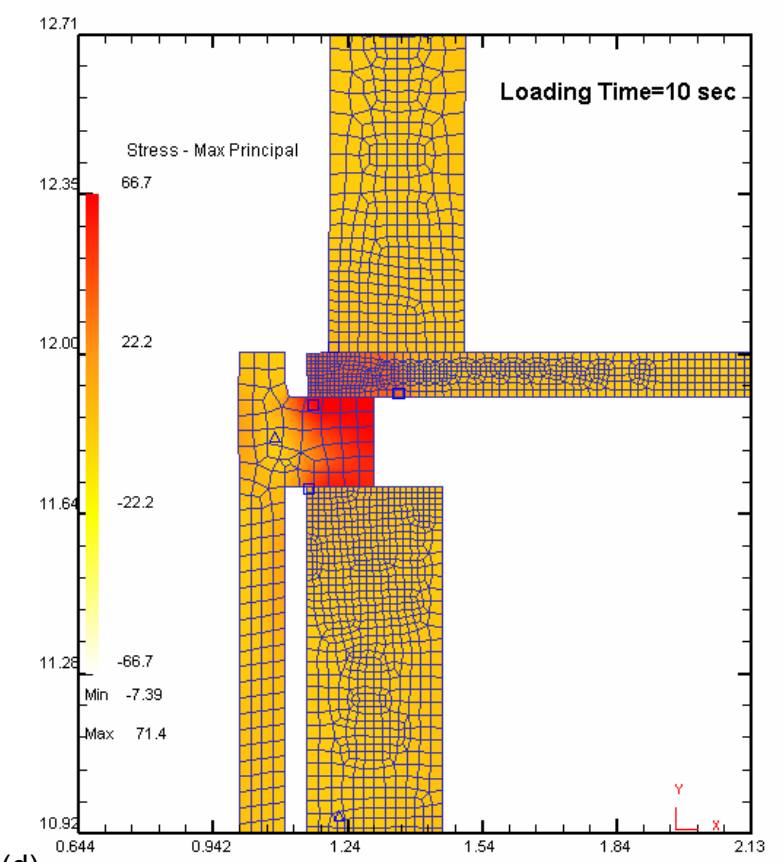

(b)

Figure 13.-(a) Temperature distribution in the various objects of the setup at the end of current flow, i.e., after $t=2$ sec.,

(b) Effective stress distribution in the various objects of the setup at the end of the force application period, i.e., at 10 sec.,

(c) Effective strain distribution in the various objects of the setup at the end of the force application and cooling period, (d) Maximum principal stress distribution in the various objects of the setup at the end of the force application and cooling period. Applied voltage $=3$. The plate and the tube are made of SS316 and IN625, respectively. 


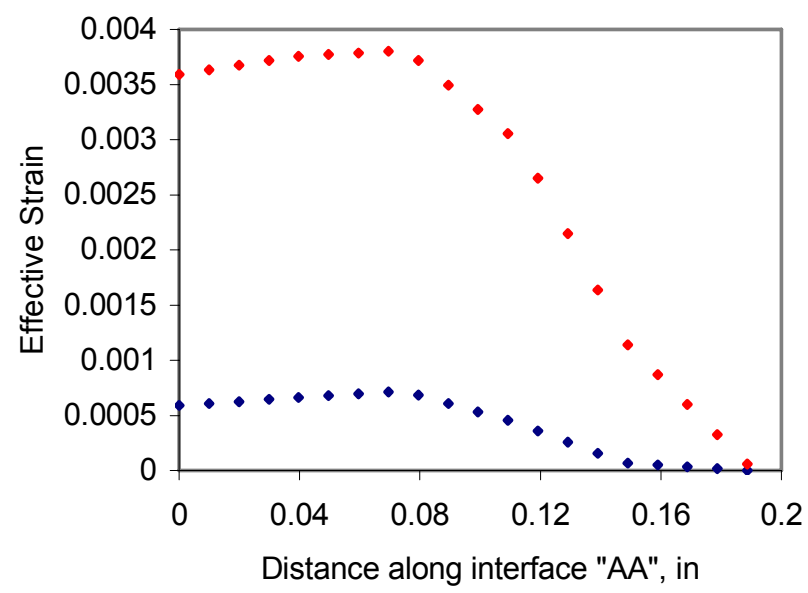

(a)

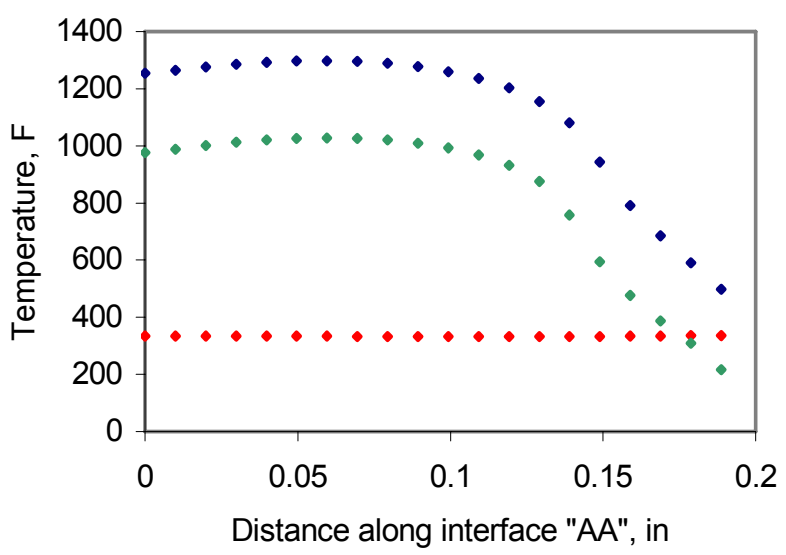

(b)

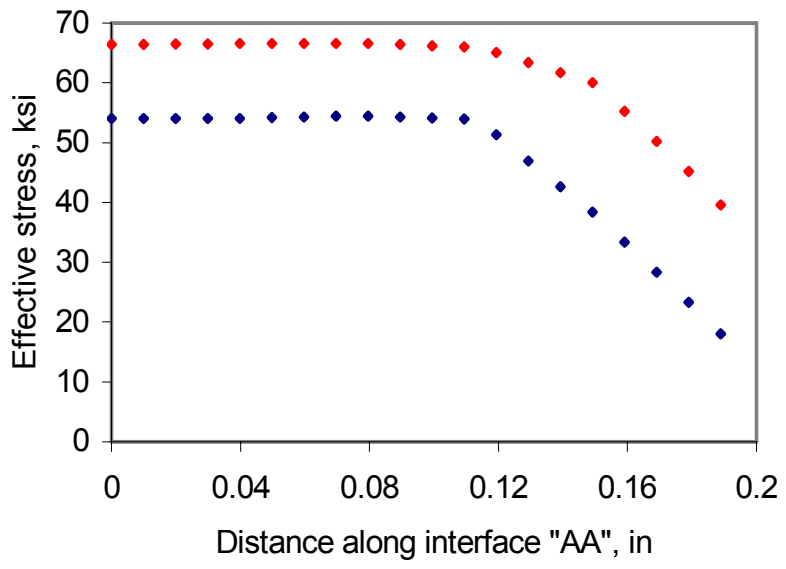

Figure 14.-(a) Temperature, (b) effective strain and, (c) effective stress distribution along the to-be-welded joint interface "AA" between the tube and the plate. Green color-at the end of $1 \mathrm{sec}$ of heating, Blue color-at the end of heating and right after load application, Red color-at the end of loading and cooling. 


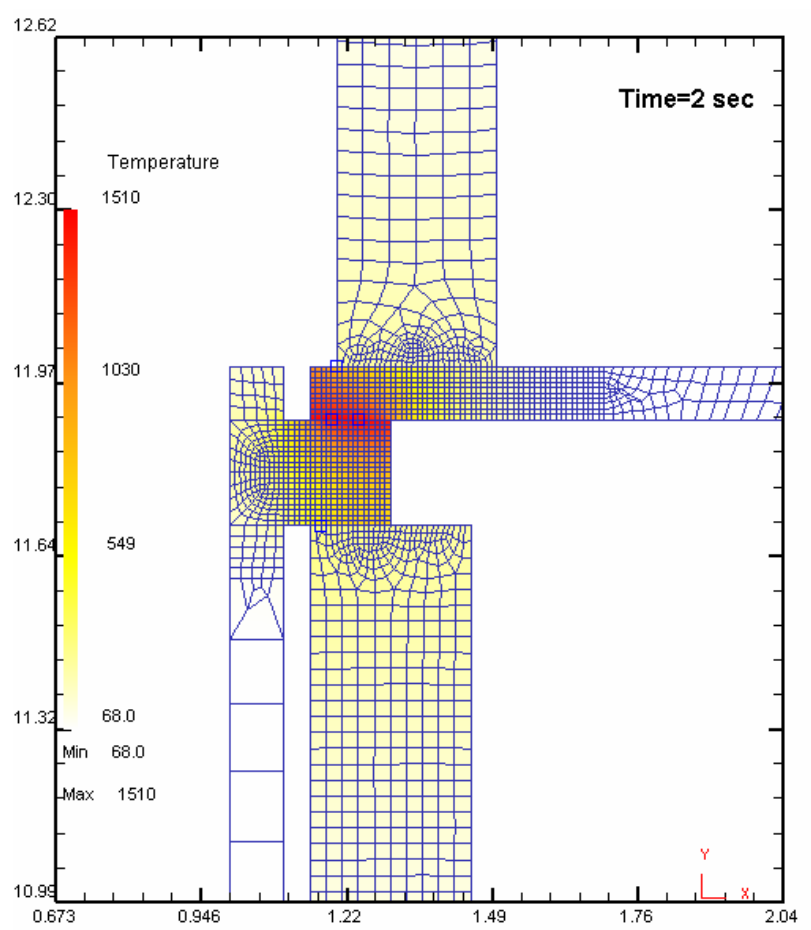

(a)

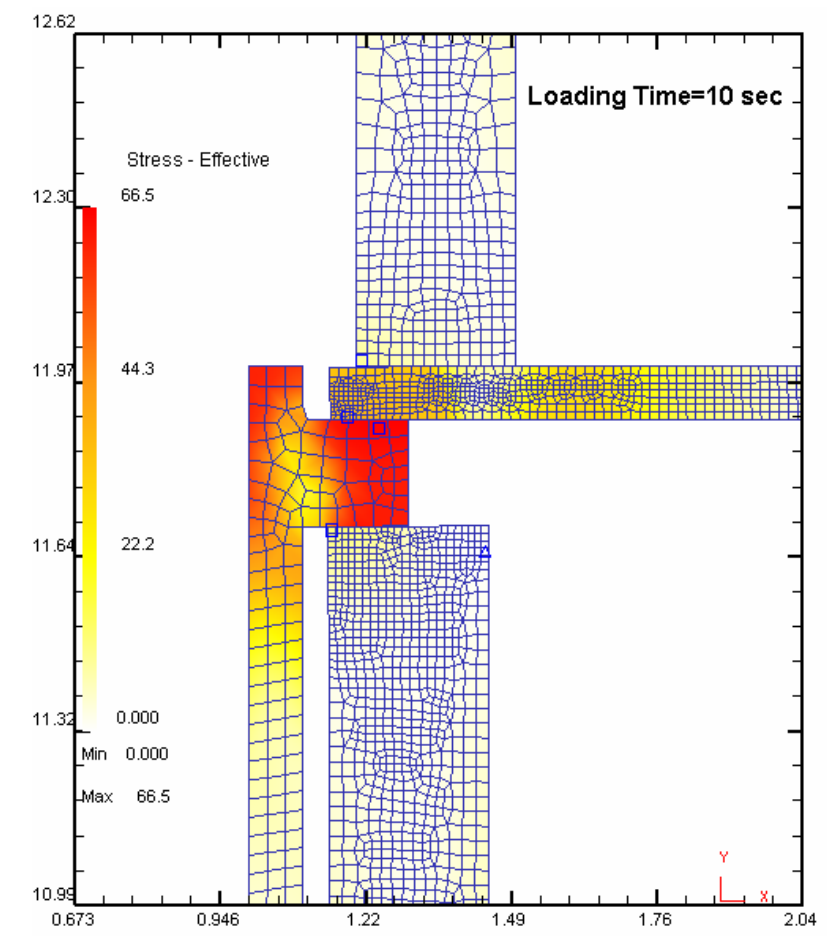

(b)

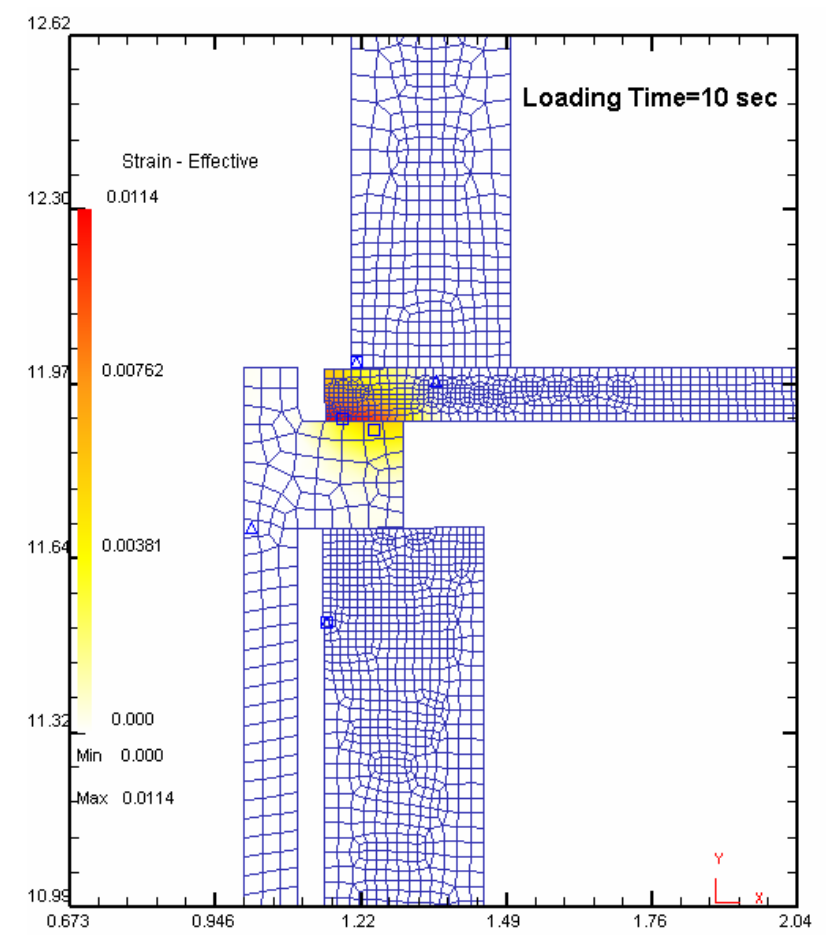

(c)

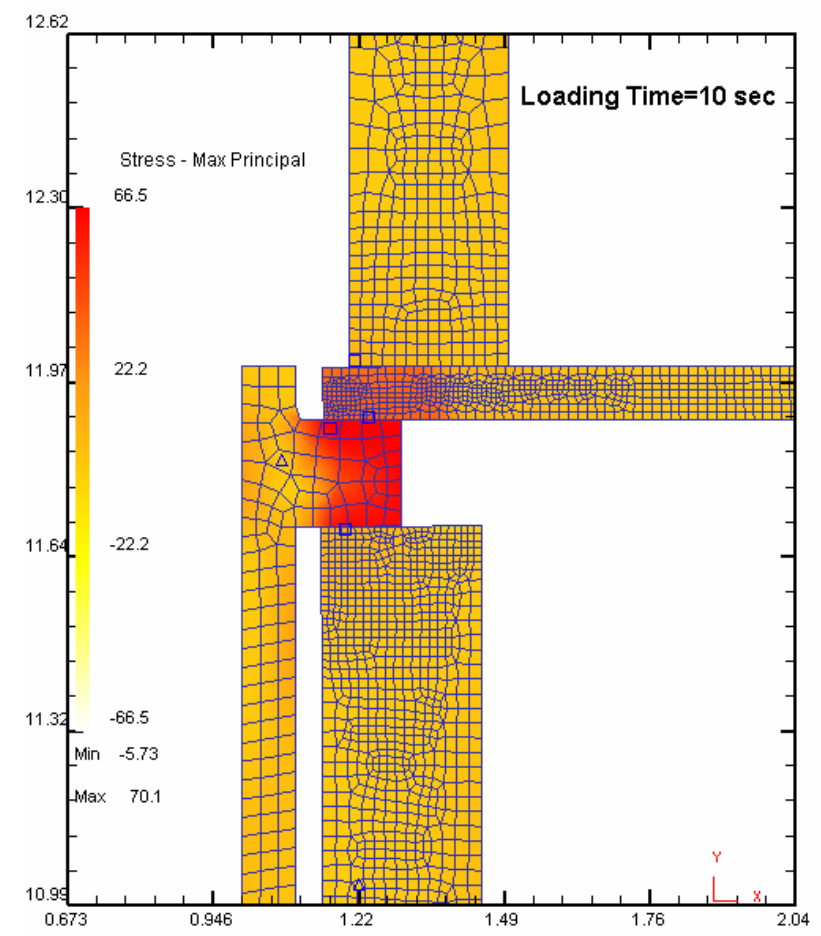

(d)

Figure 15.-(a) Temperature distribution in the various objects of the setup at the end of current flow, i.e., after $t=2$ sec.,

(b) Effective stress distribution in the various objects of the setup at the end of the force application period, i.e., at 10 sec.,

(c) Effective strain distribution in the various objects of the setup at the end of the force application and cooling period, (d) Maximum principal stress distribution in the various objects of the setup at the end of the force application and cooling period. Applied voltage $=3.3$. The plate and the tube are made of SS316 and IN625, respectively. 


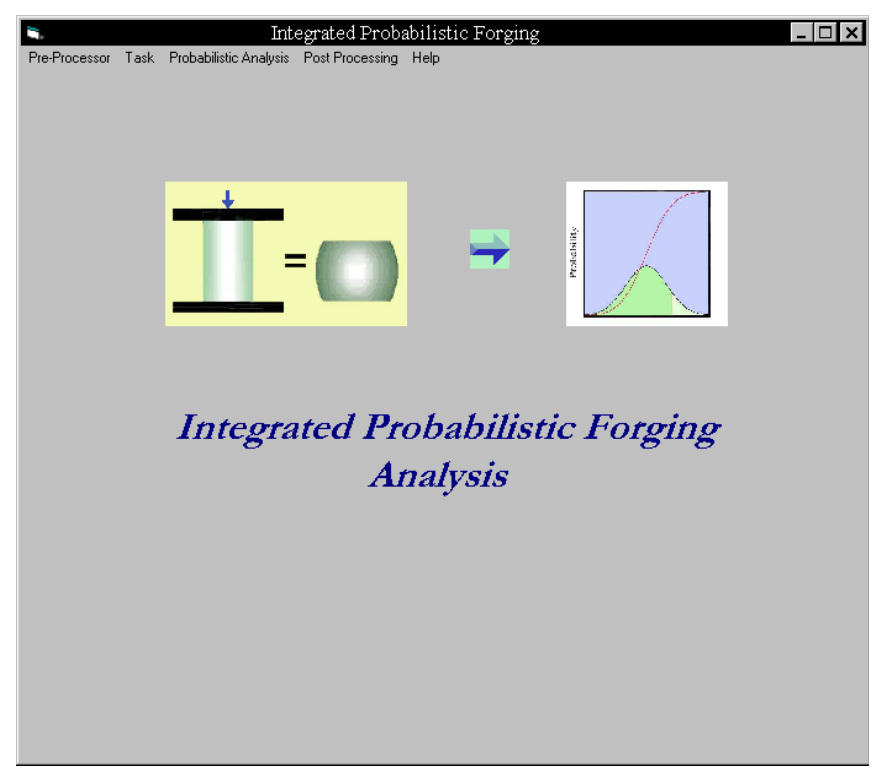

Figure 16.-Basic layout and description of the "ForgProb" interface.

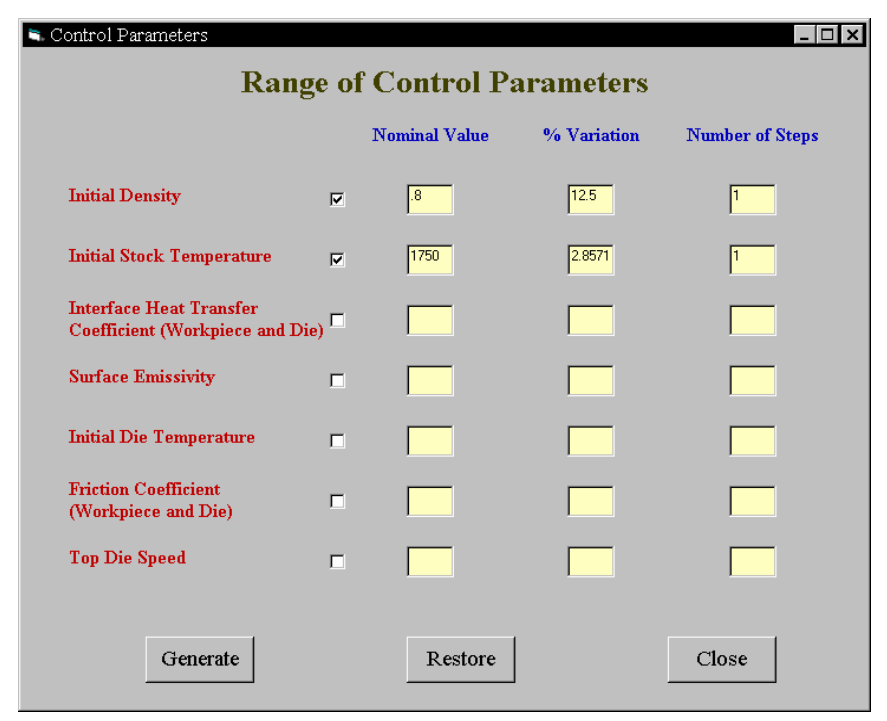

Figure 17._-“Control Parameter” panel for forging simulation.

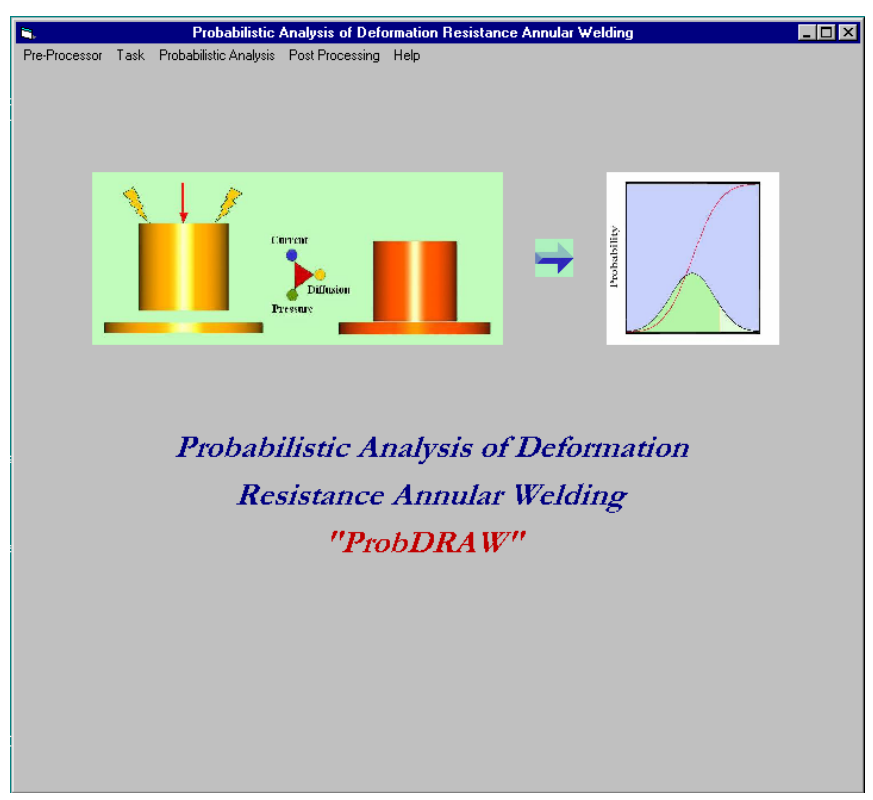

Figure 18.-Basic layout and description of the "ProbDRAW" interface.

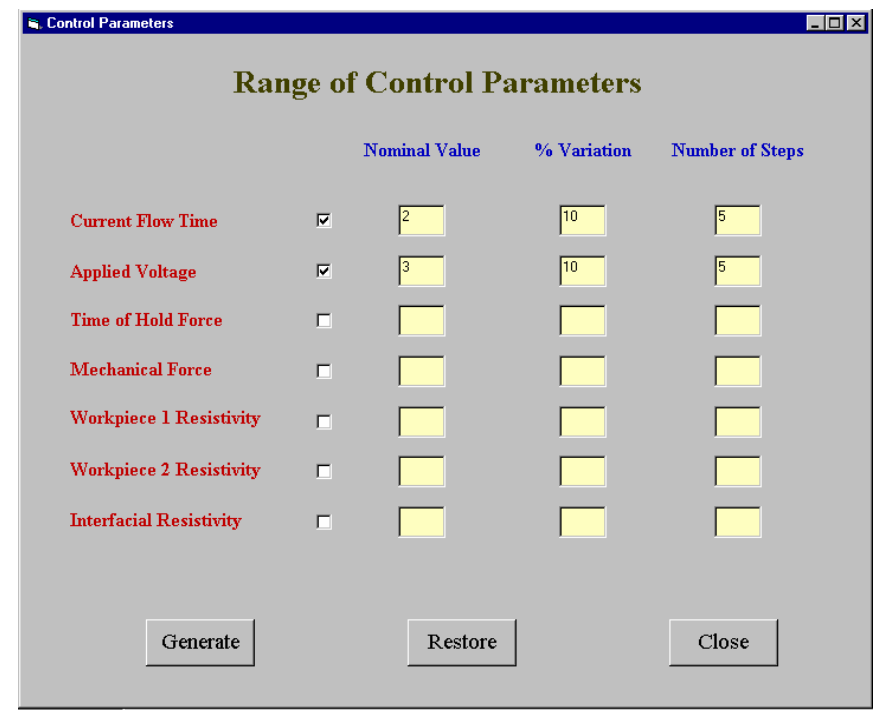

Figure 19._- “Control Parameter” panel for DRW simulation. 


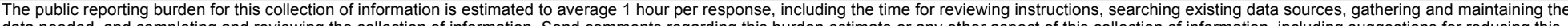

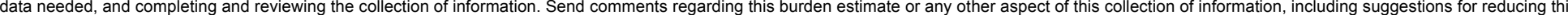

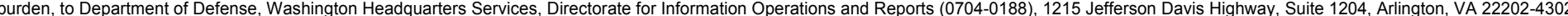

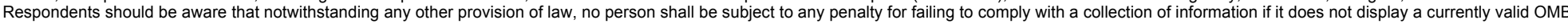
control number.

PLEASE DO NOT RETURN YOUR FORM TO THE ABOVE ADDRESS.

\section{REPORT DATE (DD-MM-YYYY) \\ 2. REPORT TYPE \\ 3. DATES COVERED (From - To)}

01-10-2007

Technical Memorandum

\section{TITLE AND SUBTITLE}

Development of Probabilistic Structural Analysis Integrated With Manufacturing Processes

\section{5a. CONTRACT NUMBER}

5b. GRANT NUMBER

5c. PROGRAM ELEMENT NUMBER

\section{AUTHOR(S)}

Pai, Shantaram, S.; Nagpal, Vinod, K.

\section{5d. PROJECT NUMBER}

5e. TASK NUMBER

5f. WORK UNIT NUMBER

WBS 685676.02.99.03.02

8. PERFORMING ORGANIZATION REPORT NUMBER

E-16154

National Aeronautics and Space Administration

John H. Glenn Research Center at Lewis Field

Cleveland, Ohio 44135-3191

\section{SPONSORING/MONITORING AGENCY NAME(S) AND ADDRESS(ES)}

National Aeronautics and Space Administration

Washington, DC 20546-0001

\section{SPONSORING/MONITORS ACRONYM(S) \\ NASA \\ 11. SPONSORING/MONITORING REPORT NUMBER \\ NASA/TM-2007-214989}

\section{DISTRIBUTION/AVAILABILITY STATEMENT}

Unclassified-Unlimited

Subject Category: 39

Available electronically at http://gltrs.grc.nasa.gov

This publication is available from the NASA Center for AeroSpace Information, 301-621-0390

\section{SUPPLEMENTARY NOTES}

\section{ABSTRACT}

An effort has been initiated to integrate manufacturing process simulations with probabilistic structural analyses in order to capture the important impacts of manufacturing uncertainties on component stress levels and life. Two physics-based manufacturing process models (one for powdered metal forging and the other for annular deformation resistance welding) have been linked to the NESSUS structural analysis code. This paper describes the methodology developed to perform this integration including several examples. Although this effort is still underway, particularly for full integration of a probabilistic analysis, the progress to date has been encouraging and a software interface that implements the methodology has been developed. The purpose of this paper is to report this preliminary development.

\section{SUBJECT TERMS}

Structural analysis; Manufacturing; Welding; Powder; Forging

\begin{tabular}{|c|c|c|c|c|}
\hline 16. SECURI & ASSIFICATION & & 17. LIMITATION OF & 18. NUMBER \\
\hline $\begin{array}{l}\text { a. REPORT } \\
U\end{array}$ & $\begin{array}{l}\text { b. ABSTRACT } \\
U\end{array}$ & $\begin{array}{l}\text { c. THIS } \\
\text { PAGE } \\
\text { U }\end{array}$ & UU & $\begin{array}{c}\text { PAGES } \\
24\end{array}$ \\
\hline
\end{tabular}

19a. NAME OF RESPONSIBLE PERSON

STI Help Desk (email:help@sti.nasa.gov) 19b. TELEPHONE NUMBER (include area code) 301-621-0390 

